\title{
Optimal Capital Structure and Industry Dynamics
}

\author{
JIANJUN MIAO*
}

\begin{abstract}
This paper provides a competitive equilibrium model of capital structure and industry dynamics. In the model, firms make financing, investment, entry, and exit decisions subject to idiosyncratic technology shocks. The capital structure choice reflects the tradeoff between the tax benefits of debt and the associated bankruptcy and agency costs. The interaction between financing and production decisions influences the stationary distribution of firms and their survival probabilities. The analysis demonstrates that the equilibrium output price has an important feedback effect. This effect has a number of testable implications. For example, high growth industries have relatively lower leverage and turnover rates.
\end{abstract}

THE INTERACTION BETWEEN CAPITAL STRUCTURE and product market decisions has recently received considerable attention in both economics and finance. Beginning with Brander and Lewis $(1986,1988)$ and Maksimovic (1988), a growing number of theoretical papers investigate this interaction. In addition, many empirical studies (Chevalier (1995a, 1995b), Phillips (1995), Kovenock and Phillips (1997), Maksimovic and Phillips (1998), Zingales (1998), Lang, Ofek, and Stulz (1996), Mackay and Phillips (2004)) examine the relation between capital structure and firm entry, exit, investment and output decisions. ${ }^{1}$ These studies generally document the following:

(1) Industry output is negatively associated with the average industry debt ratio.

(2) Plant closings are positively associated with debt and negatively associated with plant-level productivity.

(3) Firm entry is positively associated with debt of incumbents.

(4) Firm investment is negatively associated with debt.

(5) There is substantial inter- and intra-industry variation in leverage.

*Jianjun Miao is at the Department of Economics, Boston University. I thank Larry Epstein and Erwan Morellec for constant support and advice. I also thank seminar participants at many institutions, especially, Rui Albuquerque, Mike Barclay, Dan Bernhardt, Pierre Collin-Dufresne, Chris Hennessy, Ludger Hentschel, Burton Hollifield, Hugo Hopenhayn, Boyan Jovanovic, Larry Kotlikoff, Hayne Leland, John Long, Hanno Lustig, Josef Perktold, Victor Rios-Rull, Marc Rysman, Jacob Sagi, Nancy Stokey, Sheridan Titman, and Neng Wang for helpful comments. I am also grateful to an anonymous referee and the editor Robert Stambaugh for extremely helpful comments and suggestions.

${ }^{1}$ Early studies that relate the cross-sectional behavior of leverage to industry characteristics include Bradley, Jarrell, and Kim (1984) and Titman and Wessels (1988), among others. 
It is well known that debt causes the underinvestment and asset substitution problems identified by Myers (1977) and Jensen and Meckling (1976). However, it is important to emphasize that simply taking leverage as an exogenous regressor may be misleading. This is because rational firms may anticipate the effect of leverage on product/input market behavior so that the latter may influence capital structure choices. This endogeneity problem makes the interpretation of the above empirical evidence controversial. As pointed out by Zingales (1998, p. 905), "in the absence of a structural model we cannot determine whether it is the product market competition that affects capital structure choices or a firm's capital structure that affects its competitive position and its survival."

The main contribution of my paper is to fill this theoretical gap by providing an industry equilibrium model in which capital structure choices and production decisions are simultaneously influenced by the same exogenous factors. The second contribution of my paper is related to industrial organization. Many empirical studies in industrial organization have documented cross-industry differences in firm turnover. However, little theoretical research has been devoted to understanding the impact of financing policies on firm turnover. ${ }^{2}$ The present paper adds to this literature both by showing how the interaction between financing and production decisions influences firm turnover and by providing new testable predictions regarding its determinants.

The basic structure of the model is as follows. The model features a continuum of firms facing idiosyncratic technology shocks. These firms are controlled by shareholders and make financing, entry, exit, and production decisions. The capital structure choice is modeled by incorporating approaches of Modigliani and Miller (1958, 1963), Kraus and Litzenberger (1973), and Jensen and Meckling (1976). ${ }^{3}$ Moreover, this choice reflects the equilibrium interaction between financing and production/investment decisions. Specifically, production/investment decisions are chosen to maximize equity value after debt is in place so that shareholder-bondholder conflicts lead to agency costs as in Jensen and Meckling (1976) and Myers (1977). ${ }^{4}$ The initial capital structure choice, made ex ante, trades off the tax benefits of debt versus the associated bankruptcy and agency costs. Thus, the model departs from the standard Modigliani-Miller framework.

In a long-run stationary industry equilibrium, there is a stationary distribution of surviving firms. These firms exhibit a wide variation of leverage.

\footnotetext{
${ }^{2}$ See Caves (1998) for a survey of the empirical literature on firm turnover. See Jovanovic (1982), Hopenhayn (1992a, 1992b), and Ericson and Pakes (1995) for important theoretical models of industry dynamics. All these papers assume that firms are all-equity financed.

${ }^{3}$ See Harris and Raviv (1991) for a survey of the theory of capital structure. They point out that "with regard to further theoretical work, it appears that models relating to products and inputs are underexplored, while the asymmetric information approach has reached the point of diminishing returns." (pp. 299-300)

${ }^{4}$ I do not consider conflicts between shareholders and managers. Morellec (2004) examines these conflicts in a contingent claims framework.
} 
Furthermore, all industry-wide equilibrium variables are constant over time, although individual firms are continually adjusting, with some of them expanding, others contracting, some starting up, and others closing down.

I derive a closed-form solution for the unique stationary equilibrium so that the model can be analyzed tractably. I also study the effects on the equilibrium of changes in growth of technology, riskiness of technology, starting distribution of technology, fixed operating cost, entry cost, bankruptcy cost, and corporate tax.

I now highlight the main mechanism operating in the model by an example. Consider the effect of an increase in technology growth in a risk-neutral environment. First, this increase has a cash flow effect, in the sense that operating profits are higher. It also has an option effect in the sense that it changes the expected appreciation in the value of the option to default. These two effects raise firm value and the benefit of remaining active. Thus, the firm is less likely to default, and has lower expected bankruptcy costs. The standard single-firm tradeoff theory then predicts that the firm should issue more debt. However, the prediction that high growth firms have high leverage is refuted by many empirical studies (see Rajan and Zingales (1995), Barclay, Morellec, and Smith (2002), and references cited therein).

In the present industry equilibrium model, there is an important price feedback effect associated with an increase in technology growth. That is, potential entrants will anticipate increased firm value and hence prefer to enter the industry. As a result, product market competition causes the output price to fall. The decreased output price influences the firm's financing and liquidation/exit decisions. In particular, in contrast to standard singlefirm tradeoff models, this feedback effect may dominate so as to raise exit probabilities, lower coupon payments, and lower the average industry leverage ratio.

The model also has important implications for industry dynamics. Specifically, an increase in the rate of technology growth and the induced increase in the exit threshold have a selection effect in that the stationary distribution of surviving firms changes. This selection effect causes inefficient firms to exit and be replaced by new entrants, thereby leading to higher industry output and a lower turnover rate.

The present paper relates to three strands of literature. One strand beginning with Black and Scholes (1973) and Merton (1974) is in the framework of dynamic contingent claims analysis. Brennan and Schwartz (1984), Mello and Parsons (1992), Mauer and Triantis (1994), and Titman and Tsyplakov (2002) analyze the interaction between investment and financing decisions using numerical methods. Dixit (1989) studies entry and exit decisions under all-equity financing. Leland (1994, 1998), Leland and Toft (1996), Goldstein, Ju, and Leland (2001), and Morellec (2001) analyze corporate asset valuation and optimal capital structure using analytical methods. All these models consider a singlefirm environment. Under perfect competition, Leahy (1993) analyzes entry and exit under all equity financing in an industry equilibrium framework. Fries, Miller, and Perraudin (1997) generalize Leahy's model and study how entry 
and exit affect corporate asset valuation and capital structure. ${ }^{5}$ Lambrecht (2001) analyzes the impact of debt financing on entry and exit in an oligopoly environment.

Another strand is based on the framework developed by Hopenhayn (1992a, 1992b) and Hopenhayn and Rogerson (1993), where the concept of stationary equilibrium is introduced to analyze industry dynamics. Dixit and Pindyck (1994, Chapter 8) study industry investment in a similar framework. They assume firms exit the industry exogenously through sudden deaths. Most papers in this strand assume that firms are all-equity financed. Cooley and Quadrini (2001) introduce capital structure decisions into this framework and study how financial frictions account for the negative dependence of firm dynamics (growth, job reallocation, and exit) on size and age. They assume exogenous exit and consider standard one-period debt contracts based on asymmetric information.

The third strand of literature is based on strategic models. Some papers in this strand (Brander and Lewis (1986, 1988) and Maksimovic (1988)) argue that product market competition becomes "tougher" when leverage increases, while others (e.g., Poitevin (1989), Bolton and Scharfstein (1990), Dasgupta and Titman (1998)) reach the opposite conclusion. Since most models in this strand are essentially static, it seems that they are not suitable to address the questions of industry dynamics and corporate asset valuation.

My model combines elements of the first two strands of literature. In particular, I incorporate capital structure decisions into the framework of Hopenhayn (1992a), using the contingent claims analysis. This allows me to derive a number of new predictions regarding the relation between leverage and firm turnover. My model is also closely related to Fries et al. (1997) and Lambrecht (2001). Unlike Lambrecht (2001), I study perfectly competitive industries. In addition, unlike these two papers, where uncertainty comes from aggregate industry demand shocks, I assume that firms face idiosyncratic technology shocks as in Hopenhayn (1992a). The basic intuition behind the difference between firm-specific shocks and industry-wide shocks is explained in Dixit and Pindyck (1994, Chapter 8).

The remainder of the paper is organized as follows. Section I sets up the model. Section II studies a single firm's optimal capital structure choice in an industry setting. Section III derives closed-form solutions for the unique equilibrium. Section IV analyzes properties of the equilibrium. Section V concludes. Technical details are relegated to appendices.

\section{The Model}

Consider an industry consisting of a large number of firms. Suppose information is perfect and all investors are risk neutral and discount future cash

\footnotetext{
${ }^{5}$ Maksimovic and Zechner (1991) present a three-period industry equilibrium model in which firms can adopt different technologies. They do not study entry and exit decisions. See Williams (1995) for an extension in a four-period model.
} 
flows at a constant risk-free rate $r>0$. The assumption of risk neutrality does not lose any generality. If agents are risk averse, the analysis may be conducted under the risk-neutral measure (see Harrison and Kreps (1979)).

Time is continuous and varies over $[0, \infty)$. Uncertainty is represented by a probability space $(\Omega, \mathcal{F}, \mathbb{P})$ over which all stochastic processes are defined. The objective is to study long-run stationary industry equilibria in which all industry-wide aggregate variables are constant (see Section I.D for a formal definition). In particular, the equilibrium output price is constant, and there is an equilibrium stationary distribution of surviving firms.

\section{A. Industry Demand}

Industry demand is given by a decreasing function. For simplicity, take the following iso-elastic functional form:

$$
p=Y^{-\frac{1}{\varepsilon}}
$$

where $p$ is the output price, $Y$ is the industry output, and $\varepsilon>0$ is the price elasticity of demand.

\section{B. Firms}

There is a continuum of firms. Firms behave competitively, taking prices of output and input as given. At each date, each firm suffers independently exogenous death under the Poisson process with parameter $\eta>0$. This assumption captures the fact that some firms exit the industry for reasons that are not related to bankruptcy. In addition, it is important to ensure the existence of a stationary distribution of firms, since the technology shock is a nonstationary process, as I describe next.

\section{B.1. Technology}

Each firm rents capital at the rental rate $R$ to produce output with the production function $F: \mathbb{R}_{+} \rightarrow \mathbb{R}_{+}, F(k)=k^{v}$, where $v \in(0,1)$. The decreasing-returnsto-scale assumption ensures that the firm's profit is positive so that the decision problem of entry and exit studied below is meaningful. Capital depreciates continuously at a constant rate $\delta>0$. Thus, the rental rate $R$ is equal to $r+\delta$.

Firms are ex ante identical in that their technology or productivity shocks are drawn from the same distribution. They differ ex post in the realization of idiosyncratic shocks. Suppose that there is no aggregate uncertainty, and a law of large numbers for a continuum of random variables is such that industry aggregates are constant (see Judd (1985), Feldman and Gilles (1985), and Miao (2004) for discussion in the discrete time case).

For an individual firm, the technology shock process $\left(z_{t}\right)_{t \geq 0}$ is governed by a geometric Brownian motion 


$$
d z_{t} / z_{t}=\mu_{z} d t+\sigma_{z} d W_{t}
$$

where $\mu_{z}$ and $\sigma_{z}$ are positive constants. Here $\left(W_{t}\right)_{t \geq 0}$ is a standard Brownian motion representing firm-specific uncertainty.

\section{B.2. Profit Function}

At each time, each firm incurs a fixed operating $\operatorname{cost} c_{f}>0$ to produce output. Corporate income is taxed at the rate $\tau$ with full loss-offset provisions. ${ }^{6}$ Define the after-tax profit function $\Psi$ as

$$
\Psi(z ; p)=\max _{k \geq 0}(1-\tau)\left(p z F(k)-\delta k-c_{f}\right)-r k .
$$

Note that according to the U.S. tax system, the depreciation of capital is taxdeductible, but the interest cost of capital is not. Profit maximization implies the following neoclassical investment rule:

$$
p z F^{\prime}(k)=r /(1-\tau)+\delta .
$$

That is, the marginal product of capital is equal to the tax-adjusted user cost of capital. Using this equation, one can solve for the capital demand and output supply

$$
\begin{aligned}
k(z ; p) & =z^{\gamma}\left(\frac{p v}{r /(1-\tau)+\delta}\right)^{\gamma}, \\
y(z ; p)=z F(k(z ; p)) & =z^{\gamma}\left(\frac{p v}{r /(1-\tau)+\delta}\right)^{\nu \gamma},
\end{aligned}
$$

where I define

$$
\gamma \equiv \frac{1}{1-v}
$$

Substituting the above equations into (3) yields the after-tax profit function

$$
\Psi(z ; p)=(1-\tau)\left[a(p) z^{\gamma}-c_{f}\right],
$$

where

$$
a(p) \equiv p^{\gamma}(1-\nu)\left(\frac{v}{r /(1-\tau)+\delta}\right)^{\nu \gamma} .
$$

It is convenient to define the before-tax profit function

$$
\pi(z ; p) \equiv a(p) z^{\gamma}-c_{f} .
$$

This function will be used repeatedly below.

\footnotetext{
${ }^{6}$ I abstract from personal taxes in the paper.
} 


\section{B.3. Debt Contracts}

Because interest payments to debt are tax deductible, each firm has an incentive to issue debt. In order to stay in a time-homogenous environment, I consider debt contracts with infinite maturity, as in Leland (1994) and Duffie and Lando (2001). Debt is issued at par. The debt contract specifies a perpetual flow of coupon payments $b$ to bondholders. The remaining cash flows from operation accrue to shareholders. If the firm defaults on its debt obligations, it is immediately liquidated. Upon default, bondholders get the liquidation value and shareholders get nothing.

\section{B.4. Liquidation Value}

Suppose that debt reorganization is so costly that after default the firm is immediately liquidated and exits the industry. ${ }^{7}$ I model liquidation value as a fraction $\alpha \in(0,1)$ of the unlevered firm value $A(z ; p)$. The remaining fraction accounts for bankruptcy costs. One can model liquidation value as a general function of the output price $X(p)$ as in Fries et al. (1997). Here, I follow Mello and Parsons (1992). Unlevered firm value is equal to the after-tax present value of profits, plus the option value associated with abandonment opportunities. Normalize the abandonment value of the firm to zero. The firm then chooses an abandonment time $T$ so that unlevered firm value can be formally described as

$$
A(z ; p)=(1-\tau) \sup _{T \in \mathcal{T}} E^{z}\left[\int_{0}^{T} e^{-(r+\eta) t} \pi\left(z_{t} ; p\right) d t\right],
$$

where the maximization is over the set $\mathcal{T}$ of all stopping times relative to the filtration generated by the Brownian motion $\left(W_{t}\right)_{t \geq 0}, E^{z}$ is the expectation operator for the process $\left(z_{t}\right)_{t \geq 0}$ starting at $z$, and the factor $e^{-\eta t}$ accounts for the possibility of Poisson deaths.

\section{B.5. Investment and Liquidation Decisions}

At each date $t$, after servicing coupon payments $b$, residual cash flows $(1-\tau)\left(p z_{t} F\left(k_{t}\right)-\delta k_{t}-c_{f}-b\right)-r k_{t}$ are distributed to shareholders as dividends. Shareholders select the investment and default policy to maximize the value of their claims, taking price $p$ as given. Assume that default is triggered by the decision of shareholders to cease raising additional equity to meet the coupon payment, as in Mello and Parsons (1992), Leland (1994), Fries et al. (1997), Lambrecht (2001), and Duffie and Lando (2001).

The following problem describes the investment and liquidation decisions made by a typical firm with the current level of technology shock $z$ and coupon payment $b$ :

\footnotetext{
${ }^{7}$ This assumption could be relaxed by allowing debt to be reorganized through, for example, debt exchange offers as in Mella-Barral (1995) and Lambrecht (2001). This kind of analysis is, however, beyond the scope of this paper.
} 


$$
\begin{aligned}
& e(z, b ; p) \\
& \quad=\sup _{\left(k_{t}\right)_{t \geq 0}, T \in \mathcal{T}} E^{z}\left\{\int_{0}^{T} e^{-(r+\eta) t}\left[(1-\tau)\left(p z_{t} F\left(k_{t}\right)-\delta k_{t}-c_{f}-b\right)-r k_{t}\right] d t\right\} .
\end{aligned}
$$

Using the previously defined before-tax profit function, one can rewrite this problem as

$$
e(z, b ; p)=\sup _{T \in \mathcal{T}}(1-\tau) E^{z}\left[\int_{0}^{T} e^{-(r+\eta) t}\left(\pi\left(z_{t} ; p\right)-b\right) d t\right],
$$

where $\pi\left(z_{t} ; p\right)$ is given in (9). The expression $e(z, b ; p)$ represents the equity value of the firm. Since one can show that it is increasing in $z$, the default decision is described by a trigger policy whereby the firm is immediately liquidated and exits the industry once its technology shock $\left(z_{t}\right)_{t \geq 0}$ falls below an endogenously determined threshold $z_{d}(b ; p)$ (see Duffie and Lando (2001)). In what follows, without risk of confusion, I may simply use $z_{d}$ to denote $z_{d}(b ; p)$.

The equity-value-maximizing investment policy is similar to that described by the neoclassical rule (4). The difference is that here, investment takes place only in the no-default region $z>z_{d}(b ; p)$. This is related to the underinvestment problem of debt pointed out by Myers (1977) and is consistent with the empirical evidence mentioned in the introduction.

Notice that the limited liability feature of equity is embodied in problem (11) since equity value is always positive before default $\left(z>z_{d}(b ; p)\right)$, and is zero only upon default $\left(z=z_{d}(b ; p)\right)$.

\section{B.6. Debt Value and Firm Value}

The arbitrage-free value of debt is equal to the sum of the present value of coupon payments accruing to bondholders until the default time and the present value of liquidation value upon default. That is, debt value $d(z, b ; p)$ is given by

$$
d(z, b ; p)=E^{z}\left[\int_{0}^{T_{z_{d}}} e^{-(r+\eta) t} b d t\right]+\alpha A\left(z_{d} ; p\right) E^{z}\left[e^{-(r+\eta) T_{z_{d}}}\right],
$$

where $T_{y}$ denotes the first time that the process $\left(z_{t}\right)_{t \geq 0}$ falls to some boundary value $y>0$. Firm value $v(z, b ; p)$ is the sum of equity value and debt value,

$$
v(z, b ; p)=e(z, b ; p)+d(z, b ; p) .
$$

\section{B.7. Entry and Financing}

At each date there is a continuum of potential entrants. Upon entry firms incur a fixed sunk cost $c_{e}$. This cost can be financed by equity and debt. After entry, a firm's initial level of technology $z$ is drawn from the distribution $\zeta$, which 
is uniform over $[z, \bar{z}]$. This firm is then in the same position as an incumbent with the initial level of technology $z$. However, firms differ over time because they may experience different idiosyncratic shocks. Note that the uniform entry distribution is important to derive a closed-form solution for the stationary distribution of incumbents.

Assume that $\underline{z}>z_{d}(b ; p)$. Since $z_{d}$ is endogenous, this assumption must be verified in equilibrium. I rule out the case in which the initial draw of the technology shock is below the default threshold so that the entrant is immediately liquidated and exits the industry.

Before entry, firms are identical and they do not know their initial technology levels and subsequent random evolution of technology. In a competitive equilibrium, if there is positive entry, then the expected benefit of entry must be equal to the entry cost. That is, the following entry condition must hold,

$$
\int_{\underline{z}}^{\bar{z}} v(z, b ; p) \zeta(d z)=c_{e} .
$$

Finally, upon entry firms may adjust the capital structure in order to balance the benefit and cost of debt. The optimal coupon rate $b^{*}(p)$ is chosen to maximize the expected value of the firm, $\int_{\underline{z}}^{\bar{z}} v(z, b ; p) \zeta(d z)$. Since all firms are ex ante identical, they choose the same optimal coupon rate. For tractability, I assume that firms do not readjust debt after entry, as in most contingent claims models of capital structure.

\section{B.8. Timeline for Decisions}

In summary, the sequence of events and the timing of decisions for a typical firm are described in Figure 1.

\section{Aggregation}

In a long-run steady state, there is a stationary distribution of surviving firms $\mu$ and a constant entry rate $N .^{8}$ Note that the distribution $\mu$ is not a probability measure. For any Borel set $\mathcal{B}$ in the real line, $\mu(\mathcal{B})$ describes the number of surviving firms whose technology shocks lie in the set $\mathcal{B}$. Since a firm exits when its technology shock falls below $z_{d}(b ; p)$, the support of $\mu$ is the interval $\left[z_{d}(b ; p), \infty\right)$. Using this stationary distribution, aggregate variables can be computed; for example, industry output supply is given by

$$
Y(\mu, b ; p)=\int_{z_{d}(b ; p)}^{\infty} y(z ; p) \mu(d z),
$$

\footnotetext{
${ }^{8}$ The entry (exit) rate is defined as the number of firms entering (going bankrupt and exiting) the industry at each time. The same term used in some empirical studies (e.g., Dunne et al. (1988)) corresponds to the turnover rate defined later.
} 
Drawn from a uniform distribution

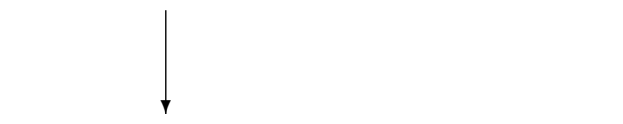

Follows a geometric

Brownian motion

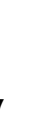

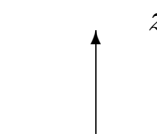

Entry financing

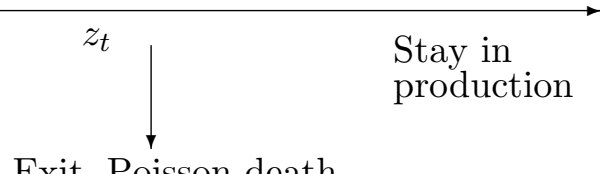

Exit, Poisson death default, liquidation

Figure 1. Timeline for decisions.

where $y(z ; p)$ is given in (5). Intuitively, suppose $z$ takes finitely many values $z_{i} \in\left[z_{d}(b ; p), \infty\right), i=1, \ldots, n$, and $\mu\left(z_{i}\right)$ is the mass of surviving firms whose technology level is $z_{i}$. Then industry output supply is given by

$$
Y(\mu, b ; p)=\sum_{i=1}^{n} y\left(z_{i} ; p\right) \mu\left(z_{i}\right)
$$

\section{Equilibrium}

A stationary industry equilibrium with exogenous leverage, $\left(p^{*}, z_{e}, N^{*}, \mu^{*}\right)$, consists of a constant output price $p^{*}$, an exit threshold $z_{e}=z_{d}\left(b ; p^{*}\right)$, an entry rate $N^{*}$, and a distribution of incumbents $\mu^{*}$ such that (i) firms solve problem (11); (ii) the market clears

$$
p^{*}=Y\left(\mu^{*}, b ; p^{*}\right)^{-1 / \varepsilon},
$$

where $Y(\cdot)$ is given in (16); (iii) the entry condition (15) holds; and, (iv) the distribution $\mu^{*}$ is an invariant measure over $\left[z_{e}, \infty\right)$.

In this equilibrium, the coupon rate $b$ is exogenously given. When $b$ is chosen to maximize firm value, the resulting equilibrium is called the stationary equilibrium with endogenous leverage. Such an equilibrium is denoted by $\left(p^{o}, z_{e}^{o}, N^{o}, \mu^{o}\right)$.

Conditions (i)-(iii) in the above definition are standard requirements for a competitive equilibrium. Condition (iv) requires that, in a long-run steady state, the distribution of firms be constant over time. This is possible because there is a continuum of firms that are subject to idiosyncratic shocks and a law of large numbers is assumed. As pointed out by Dixit and Pindyck (1994, p. 277), "at the industry level, the shocks and responses of firms can aggregate into long-run stationary conditions, so that the industry output and price are nonrandom. However, the equilibrium level of these variables is affected by the parameters of firm-specific uncertainty. Also, behind the aggregate certainty lies a great deal of randomness and fluctuations: firms enter, invest, and exit in response to the shocks to their individual fortunes." 
To better understand condition (iv), it is helpful to use a discrete time approximation similar to that in Hopenhayn (1992a). The following equation describes the evolution of firm distributions:

$$
\mu_{t+d t}(\mathcal{B})=(1-\eta d t) \int_{z_{e}}^{\infty} Q(\mathcal{B} \mid z) \mu_{t}(d z)+N^{*} \zeta([\underline{z}, \bar{z}] \cap \mathcal{B}) d t
$$

The interpretation is as follows: At any date $t$, let $\mu_{t}$ be the distribution of firms at date $t$. After an instant $d t$, firms transit to the set $\mathcal{B}$ at date $t+d t$ according to the transition function $Q(\mathcal{B} \mid z)$. Each firm survives with probability $(1-\eta d t)$. Moreover, each firm exits the industry when its technology shocks fall below $z_{e}$. Thus, the first term in (19) describes the mass of firms that lie in the set $\mathcal{B}$ at date $t+d t$. The second term in (19) describes the mass of new entrants entering the set $\mathcal{B}$. The sum of these two terms is equal to the total mass of firms that lie in the set $\mathcal{B}$ at date $t+d t$, which is $\mu_{t+d t}(\mathcal{B})$. In the long-run stationary equilibrium, this mass must not change over time. This determines the invariant distribution $\mu^{*}(\mathcal{B})$. Note that firms are identified by the technology levels $z$. The mass of firms with technology levels lying in $\mathcal{B}$ is constant over time. However, the actual identities of firms occupying these positions may keep changing.

\section{Optimal Capital Structure}

In this section, I fix the output price $p$ and consider a single firm's capital structure decision. This decision is modeled in the spirit of the standard EBITbased single-firm contingent claims models, such as Mello and Parsons (1992) and Goldstein et al. (2001). However, different from these models, investment policies are not fixed, and the product market influences the capital structure decision through the output price.

\section{A. Unlevered Firm Value}

I begin by deriving unlevered firm value. Because unlevered firm value is increasing in $z$, the solution to (10) is described by a threshold value $z_{A}$. The firm is abandoned the first time the technology shock falls below $z_{A}$. To solve for this threshold value $z_{A}$ and unlevered firm value, let

$$
A(z ; p \mid y)=(1-\tau) E^{z}\left[\int_{0}^{T_{y}} e^{-(r+\eta) t} \pi\left(z_{t} ; p\right) d t\right]
$$

be unlevered firm value given any threshold level $y>0$. Here $T_{y}$ denotes the first passage time of the process $\left(z_{t}\right)_{t \geq 0}$ starting from $z$ to $y$. The abandonment threshold $z_{A}$ is determined by the smooth-pasting condition

$$
\left.\frac{\partial A\left(z ; p \mid z_{A}\right)}{\partial z}\right|_{z=z_{A}}=0
$$

The following proposition describes unlevered firm value and the abandonment decision. 
Proposition 1: Suppose

$$
\lambda \equiv r+\eta-\mu_{z} \gamma-\sigma_{z}^{2} \gamma(\gamma-1) / 2>0 .
$$

Then unlevered firm value is given by

$$
A(z ; p)=(1-\tau) \Pi(z ; p)-(1-\tau) \Pi\left(z_{A} ; p\right)\left(\frac{z}{z_{A}}\right)^{\vartheta}, \quad z \geq z_{A},
$$

where

$$
\begin{gathered}
\vartheta \equiv \frac{1}{\sigma_{z}^{2}}\left[\left(\sigma_{z}^{2} / 2-\mu_{z}\right)-\sqrt{2(r+\eta) \sigma_{z}^{2}+\left(\sigma_{z}^{2} / 2-\mu_{z}\right)^{2}}\right]<0, \\
\Pi(z ; p) \equiv E^{z}\left[\int_{0}^{\infty} e^{-(r+\eta) t} \pi\left(z_{t} ; p\right) d t\right]=\frac{a(p)}{\lambda} z^{\gamma}-\frac{c_{f}}{r+\eta},
\end{gathered}
$$

and

$$
z_{A}(p)=\left[\frac{\vartheta \lambda c_{f}}{(\vartheta-\gamma)(r+\eta) a(p)}\right]^{1 / \gamma} .
$$

The firm is abandoned the first time its technology process falls below the threshold value $z_{A}$.

Note that $\Pi(z ; p)$ in $(25)$ represents the before-tax present value of the profit flow. Assumption (22) ensures that $\Pi(z ; p)$ is finite. Equation (23) implies that unlevered firm value is equal to the present value of after-tax profits plus the option value of abandonment. Since $\Pi\left(z_{A}, p\right)=\frac{\gamma}{\vartheta-\gamma} \frac{c_{f}}{r+\eta}<0$, the firm is not abandoned as soon as losses are incurred: Only if the firm's technology shock is bad enough, is the firm abandoned-because abandonment is irreversible and waiting has positive option value.

\section{B. Liquidation Decision and Levered Equity Value}

Recall that the firm's liquidation decision is described by a trigger policy. To solve for equity value and the optimal default threshold $z_{d}$, let

$$
e(z, b ; p \mid y)=(1-\tau) E^{z}\left[\int_{0}^{T_{y}} e^{-(r+\eta) t}\left(\pi\left(z_{t} ; p\right)-b\right) d t\right]
$$

denote the equity value when the default threshold is given by $y$ and the coupon rate is given by $b$.

Since shareholders may always cover operating losses by raising additional equity, they choose a default threshold $y$ so as to maximize equity value $e(z, b ; p \mid y)$. The optimal default threshold $z_{d}$ satisfies the smooth-pasting condition 


$$
\left.\frac{\partial e\left(z, b ; p \mid z_{d}\right)}{\partial z}\right|_{z=z_{d}}=0 .
$$

The following proposition describes equity value and liquidation decisions.

Proposition 2: Let Assumption (22) hold. Then equity value is given by

$$
\begin{aligned}
& e(z, b ; p) \\
& \quad=(1-\tau)\left[\Pi(z ; p)-\frac{b}{r+\eta}+\left(\frac{b}{r+\eta}-\Pi\left(z_{d} ; p\right)\right)\left(\frac{z}{z_{d}}\right)^{\vartheta}\right], \quad z \geq z_{d},
\end{aligned}
$$

where

$$
z_{d}(b ; p)=\left[\frac{\vartheta \lambda\left(b+c_{f}\right)}{(\vartheta-\gamma)(r+\eta) a(p)}\right]^{1 / \gamma}
$$

The firm is liquidated the first time its technology shock falls below the threshold value $z_{d}(b ; p)$.

Equation (29) implies that equity value is equal to the after-tax value of the present value of the profit flow, minus the present value of coupon payments, plus the option value of default. Similar to abandonment, default is irreversible and waiting to default has positive option value.

Using equation (25), one can rewrite equation (30) as

$$
\Pi\left(z_{d} ; p\right)=\frac{\vartheta}{\vartheta-\gamma} \frac{b}{r+\eta} .
$$

This implies that the optimal liquidation policy for shareholders consists in liquidating when the present value of the profit flow upon default $\Pi\left(z_{d} ; p\right)$ is equal to the cost of servicing debt $b /(r+\eta)$ multiplied by the factor $\vartheta /(\vartheta-\gamma) \in$ $(0,1)$ that represents an option value of waiting to default. It is important to note that product market behavior affects the liquidation decision because the output price affects the present value of the profit flow.

Equation (30) also implies that the liquidation threshold $z_{d}(b ; p)$ is increasing in $b$ and decreasing in $p$ (note that $a(p)$ given in (8) is increasing in $p$ ). Thus, higher debt or lower output prices cause the firm to exit earlier. Higher debt also induces underinvestment as in Myers (1977) in the sense that the range of the states over which investment takes place is smaller.

\section{Debt Value and Levered Firm Value}

Using the standard contingent claims analysis, one can derive debt value and firm value from equations (13)-(14).

Proposition 3: Let Assumption (22) hold. Then debt value is given by

$$
d(z, b ; p)=\frac{b}{r+\eta}+\left(\alpha A\left(z_{d} ; p\right)-\frac{b}{r+\eta}\right)\left(\frac{z}{z_{d}}\right)^{\vartheta}, \quad z \geq z_{d}
$$


and firm value is given by

$$
\begin{aligned}
v(z, b ; p)= & A(z ; p)+\frac{b \tau}{r+\eta}\left[1-\left(\frac{z}{z_{d}}\right)^{\vartheta}\right] \\
& -(1-\alpha) A\left(z_{d} ; p\right)\left(\frac{z}{z_{d}}\right)^{\vartheta}, \quad z \geq z_{d} .
\end{aligned}
$$

Equation (32) demonstrates that debt value is equal to the present value of coupon payments, plus the probability-adjusted changes in value if and when default occurs. Note that under the present specification of liquidation value, one can show that $\alpha A\left(z_{d} ; p\right)<\frac{b}{r+\eta}$, so debt is risky, that is, $d(z, b ; p)<\frac{b}{r+\eta}$.

By definition, levered firm value is the sum of equity value and debt value as given in (29) and (32). Equation (33) demonstrates that levered firm value equals unlevered firm value plus the probability-adjusted tax shield of debt minus probability-adjusted bankruptcy costs.

\section{Optimal Coupon}

Upon entry, the firm adjusts its capital structure to balance the benefit and cost of debt. Thus, it chooses an optimal coupon rate $b^{*}$ to maximize its expected value; that is,

$$
b^{*}(p) \in \arg \max _{b} \int_{\underline{z}}^{\bar{z}} v(z, b ; p) \zeta(d z) .
$$

Since it can be shown that $v$ is strictly concave in $b$, the following first-order condition determines the optimal coupon rate:

$$
\begin{aligned}
\frac{\tau}{r+\eta}\left[1-\int_{\underline{z}}^{\bar{z}}\left(\frac{z}{z_{d}}\right)^{\vartheta} \zeta(d z)\right]= & \frac{-\vartheta}{\gamma} \frac{\tau b}{(r+\eta)\left(b+c_{f}\right)} \int_{\underline{z}}^{\bar{z}}\left(\frac{z}{z_{d}}\right)^{\vartheta} \zeta(d z)+\frac{1-\alpha}{\gamma\left(b+c_{f}\right)} \\
& \times\left[A^{\prime}\left(z_{d} ; p\right) z_{d}-\vartheta A\left(z_{d} ; p\right)\right] \int_{\underline{z}}^{\bar{z}}\left(\frac{z}{z_{d}}\right)^{\vartheta} \zeta(d z),
\end{aligned}
$$

where the liquidation threshold $z_{d}$ is given by (30).

The expression on the left side of equation (35) represents the probabilityadjusted marginal tax advantage of debt and the expression on the right side represents the marginal bankruptcy cost. In particular, the first term on the right side represents the loss of marginal tax shield due to bankruptcy. The second term on the right side represents the loss of marginal liquidation value due to an inefficient choice of liquidation time by the shareholder. The optimal capital structure prescribes a coupon rate so that the marginal benefit of debt equals the marginal cost.

The present model implies that product market competition influences the firm's financing decisions since industry output prices affect the optimal coupon 
rate. This is transparent when there is no fixed operating cost $\left(c_{f}=0\right)$. In this case, there is a closed-form solution to (35),

$$
b^{*}(p)=\frac{(\vartheta-\gamma)(r+\eta) a(p)}{\vartheta \lambda}\left[\frac{\gamma-\vartheta}{\gamma}-\frac{\vartheta(1-\alpha)(1-\tau)}{\gamma \tau}\right]^{\frac{\gamma}{\vartheta}}\left[\int_{\underline{z}}^{\bar{z}} z^{\vartheta} \zeta(d z)\right]^{\frac{\gamma}{\vartheta}} .
$$

This equation implies that the optimal coupon is increasing in the output price $p$. The intuition is that when the output price $p$ is higher, the firm is less likely to default so that it prefers to issue more debt.

\section{E. Agency Costs}

Given the coupon rate $b$ and the technology shock $z$, the firm's first-best liquidation policy is to choose a liquidation threshold $z_{d}^{F B}$ so as to maximize firm value, instead of equity value. Since upon default the firm only recovers a fraction of unlevered firm value, it prefers to postpone default as long as possible in order to benefit from tax shields. However, the firm also incurs the fixed operating cost, and hence eventually suffers losses. The first-best liquidation threshold must be chosen to trade off these benefits and costs.

Due to the conflict of interest between shareholders and bondholders, the first-best liquidation policy cannot be enforced ex post. These agency costs are measured by the difference between the first-best firm value and firm value under the liquidation policy chosen by the shareholder. The following proposition describes the first-best liquidation policy, firm value, and agency costs.

Proposition 4: Let Assumption (22) hold. Then the first-best firm value is given by

$$
v^{F B}(z, b ; p)=A(z ; p)+\frac{b \tau}{r+\eta}\left[1-\left(\frac{z}{z_{A}}\right)^{\vartheta}\right],
$$

where $z_{A}$ is given by (26). Under the first-best liquidation policy, the firm is liquidated the first time its technology process falls below the threshold value $z_{A}$. The agency cost is given by

$$
c_{A}(z, b ; p)=\frac{b \tau}{r+\eta}\left[\left(\frac{z}{z_{d}}\right)^{\vartheta}-\left(\frac{z}{z_{A}}\right)^{\vartheta}\right]+(1-\alpha) A\left(z_{d} ; p\right)\left(\frac{z}{z_{d}}\right)^{\vartheta}>0 .
$$

This proposition demonstrates that the first-best liquidation threshold is equal to the abandonment threshold value $z_{A}$, that is, $z_{d}^{F B}=z_{A}$. Since Propositions 1-2 show that $z_{A}<z_{d}$, the equity-maximizing liquidation policy implies an inefficient early liquidation time. Equation (37) shows that the first-best firm value is equal to unlevered firm value plus the probability-adjusted tax shield. Equation (38) shows that agency costs consist of the loss of tax shields due to inefficient early liquidation plus the probability-adjusted liquidation costs. Since $\vartheta<0$ and $z_{A}<z_{d}$, it follows from (38) that agency costs decrease with the 
technology level $z$ for any fixed coupon rate $b$. This implies that agency costs are less severe for more efficient firms. The intuition is that more efficient firms are less likely to default and hence the loss of tax shields and probability-adjusted liquidation costs is smaller.

\section{Stationary Equilibrium}

This section analyzes the existence and uniqueness of stationary equilibrium. I first consider the case in which leverage is exogenous. Then I consider the case in which leverage is chosen to maximize firm value.

\section{A. Equilibrium with Exogenous Leverage}

Throughout this subsection, the coupon rate $b$ is assumed to be fixed exogenously. The following proposition establishes the existence and uniqueness of stationary equilibrium.

Proposition 5: Suppose

$$
\begin{aligned}
r+\eta & >\mu_{z} \gamma+\sigma_{z}^{2} \gamma(\gamma-1) / 2, \\
0 & >\gamma+\frac{1}{\sigma_{z}^{2}}\left(\mu_{z}-0.5 \sigma_{z}^{2}-\sqrt{\left(\mu_{z}-0.5 \sigma_{z}^{2}\right)^{2}+2 \sigma_{z}^{2} \eta}\right), \\
\eta & >\sigma_{z}^{2}-\mu,
\end{aligned}
$$

where $\gamma=1 /(1-v)$. Then there is a unique stationary equilibrium with the coupon rate $b \geq 0,\left(p^{*}, z_{e}, N^{*}, \mu^{*}\right)$, such that $\underline{z}>z_{e}{ }^{9}$

I first comment on the assumptions. As explained earlier, assumption (39) ensures that the present value of profits is finite. Assumption (40) ensures that certain high-order moments of the scaled stationary distribution are finite. This assumption is necessary since the stationary distribution has an infinite support and the moments are improper integrals. Assumption (41) is important for the existence of a stationary distribution. ${ }^{10}$ It simply says that the Poisson death rate cannot be too small. The reason lies in the fact that the geometric Brownian motion technology process $\left(z_{t}\right)_{t \geq 0}$ is nonstationary. Heuristically, without Poisson deaths, the number of firms with high technology levels can explode and a stationary distribution cannot exist. One needs to assume a sufficiently high death rate to prevent this explosion. From this argument, one can deduce that the Poisson death assumption is not needed if $\left(z_{t}\right)_{t \geq 0}$ is a stationary process, for example, the mean-reverting process. However, the mean-reverting technology process does not permit any intuitive closed-form solution for the stationary equilibrium. Consequently, complex numerical methods are needed. This is typical in the discrete time models (e.g., Hopenhayn (1992b), Hopenhayn

\footnotetext{
${ }^{9}$ The explicit expressions for the equilibrium are given in Appendix A.

${ }^{10}$ The same assumption is also made in Dixit and Pindyck (1994, p. 275).
} 
and Rogerson (1993), Cooley and Quadrini (2001)). Finally, the condition $z>z_{e}$ guarantees that the initial draw of the technology shock cannot be so bad that the firm has no incentive to enter the industry. Since $z_{e}=z_{d}\left(b ; p^{*}\right)$, it follows from (30) that this condition requires that the fixed cost $c_{f}$ is not too big.

Note that when there is no debt (i.e., $b=0$ ), firms are all-equity financed and the model reduces to the one similar to the discrete time industry dynamics model studied by Hopenhayn (1992a). As mentioned earlier, one important difference is that here the technology shock is modeled as a nonstationary process, whereas it is modeled as a stationary process in Hopenhayn (1992a).

I now outline the intuition behind the theorem and relegate the detailed proof to the appendix. The proof is by construction, which follows from a similar procedure described in both Hopenhayn and Rogerson (1993) and Dixit and Pindyck (1994, Chapter 8). It consists of three steps.

In the first step, I use the entry condition (15) to determine the equilibrium output price $p^{*}$. It is easy to show that firm value is strictly increasing in the output price. When the output price is high enough, expected firm value exceeds the entry $\operatorname{cost} c_{e}$, and potential entrants have incentives to enter the industry. As more firms enter the industry, market competition drives down the output price. On the other hand, when the output price is low enough, expected firm value may be lower than the entry cost. In this case, no firm prefers to enter the industry. In sum, if there is positive entry, the equilibrium output price $p^{*}$ must be such that the expected firm value equals the entry cost, which is the entry condition (15). To show that there is a unique solution $p^{*}$ to (15), observe the following: As price $p$ goes to infinity, the firm makes unbounded profits and hence firm value goes to infinity. However, as $p$ goes to zero, the firm becomes unprofitable so that it is abandoned and firm value goes to zero. Thus, a unique equilibrium output price $p^{*}$ is determined using the intermediate value theorem, as illustrated in Figure 2.

In the second step, I solve for the invariant distribution $\mu^{*}$. I first solve for the exit threshold and the support of $\mu^{*}$. Given the equilibrium output price $p^{*}$, the equilibrium exit threshold $z_{e}=z_{d}\left(b ; p^{*}\right)$ is determined using equation (30). This threshold value is exactly analogous to the corresponding formula for the single-firm liquidation decision described in Section II. The intuition is similar to that discussed in Dixit and Pindyck (1994, Chapter 8). When uncertainty is firm-specific, a firm that observes a favorable shock $z$ has an edge over its competitors. Its favorable $z$ cannot be "stolen" by competitors. Thus, a positive value of waiting does survive, and the standard single-firm option value analysis can be embedded in an industry equilibrium model.

Since inefficient firms with technology levels lower than $z_{e}$ exit the industry, the support of the stationary distribution of incumbents $\mu^{*}$ is given by $\left[z_{e}, \infty\right)$. Note that equation (19) implies that $\mu^{*}$ is linearly homogenous in the entry rate $N^{*}$. Thus, it is convenient to scale $\mu^{*}$ by the factor $N^{*}$ when solving it. In Appendix A, I derive the scaled density of $\mu^{*}$ using the method described in Dixit and Pindyck (1994, Chapter 8). The main idea of this method follows from the intuitive description given in Section I.D. That is, in order for the density to be constant over time, the rate at which firms arrive at any technology level 


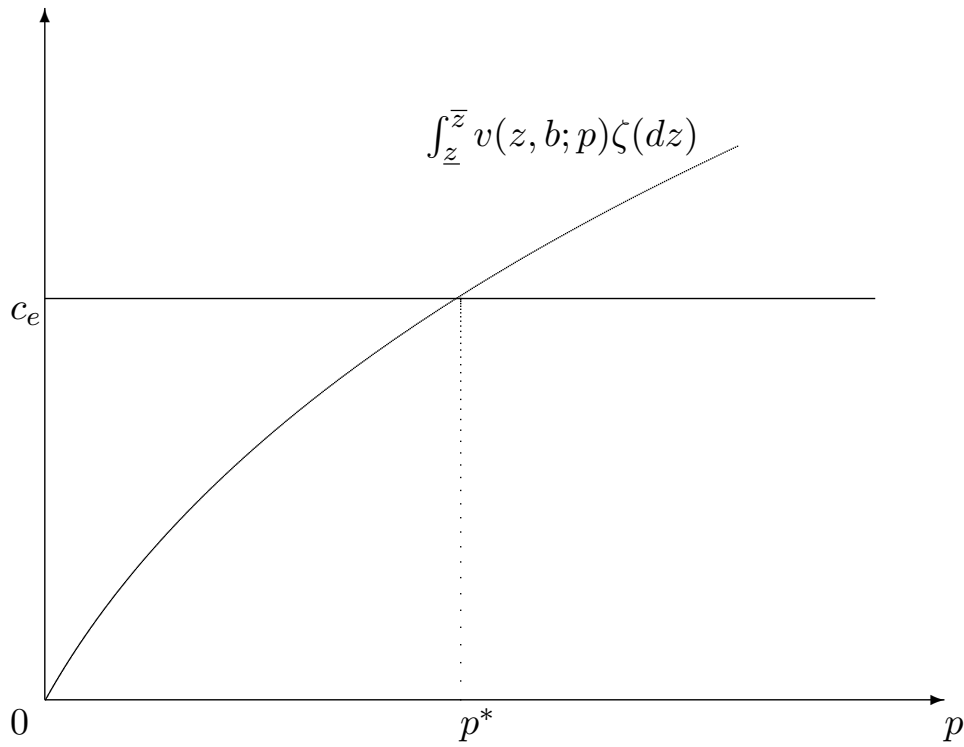

Figure 2. The determination of the equilibrium output price $p^{*}$. This figure illustrates that the equilibrium output price $p^{*}$ is determined by the entry condition-the expected firm value is equal to the entry cost.

because of entry must be equal to the rate at which firms move away from that level because of Poisson deaths or bankruptcy.

In the final step, the entry rate $N^{*}$ is determined by the market-clearing condition (18). Since the stationary distribution $\mu^{*}$ is proportional to the entry rate $N^{*}$, it follows from (16) that industry output supply $Y\left(\mu^{*}, b ; p^{*}\right)$ is also proportional to $N^{*}$. Equating the industry demand $p^{*}=Y\left(\mu^{*}, b ; p^{*}\right)^{-1 / \varepsilon}$ yields the entry rate $N^{*}$.

\section{B. Equilibrium with Endogenous Leverage}

When each firm chooses a value-maximizing capital structure, it selects the coupon rate $b^{*}(p)$ to solve problem (34). The equilibrium output price $p^{o}$ is then the solution to the following equation derived from the entry condition:

$$
\int_{\underline{z}}^{\bar{z}} v\left(z, b^{*}(p) ; p\right) \zeta(d z)=c_{e}
$$

Now, the equilibrium with endogenous leverage can be characterized in the same manner as that with exogenous leverage except for the following changes: (i) The output price $p^{*}$ is replaced by the above value $p^{o}$; (ii) the coupon rate $b$ takes the value $b^{o} \equiv b^{*}\left(p^{o}\right)$; and, (iii) the exit threshold $z_{e}$ takes the value $z_{e}^{o}=z_{e}\left(b^{o} ; p^{o}\right)$. The detailed computation of the equilibrium $\left(b^{o}, p^{o}, z_{e}^{o}, N^{o}, \mu^{o}\right)$ is described in Appendix B. 
Importantly, if there is no fixed operating cost (i.e., $c_{f}=0$ ), then the equilibrium with endogenous leverage can be characterized completely in closed form.

Proposition 6: Let Assumptions (39)-(41) hold. Also assume $c_{f}=0$. Then the unique stationary equilibrium with optimal leverage $\left(p^{o}, z_{e}^{o}, N^{o}, \mu^{o}\right)$ is characterized as follows:

$$
\begin{aligned}
& z_{e}^{o}=\left[\frac{\gamma-\vartheta}{\gamma}-\frac{\vartheta(1-\alpha)(1-\tau)}{\gamma \tau}\right]^{\frac{1}{\vartheta}}\left[\int_{\underline{z}}^{\bar{z}} z^{\vartheta} \zeta(d z)\right]^{\frac{1}{\vartheta}}, \\
& p^{o}=\left(c_{e}\right)^{\frac{1}{\gamma}}\left\{(1-v)\left(\frac{v}{r /(1-\tau)+\delta}\right)^{\nu \gamma}\left[\frac{1-\tau}{\lambda} \frac{\bar{z}^{\gamma+1}-\underline{z}^{\gamma+1}}{(\bar{z}-\underline{z})(\gamma+1)}+\frac{\tau}{\lambda}\left(z_{e}^{o}\right)^{\gamma}\right]\right\}^{-\frac{1}{\gamma}}, \\
& N^{o}=\left(p^{o}\right)^{-(\varepsilon+\gamma v)}\left(\int_{z_{e}}^{\infty} z^{\gamma} f^{o}(z) d z\right)^{-1}\left(\frac{v}{r /(1-\tau)+\delta}\right)^{-\nu \gamma},
\end{aligned}
$$

where $N^{o} f^{o}$ is the density of the stationary distribution $\mu^{o}$ and its explicit expression is given in the appendix. Moreover, the optimal coupon rate is given by

$$
b^{o}=\frac{(\vartheta-\gamma)(r+\eta) a\left(p^{o}\right)}{\vartheta \lambda}\left[\frac{\gamma-\vartheta}{\gamma}-\frac{\vartheta(1-\alpha)(1-\tau)}{\gamma \tau}\right]^{\frac{\gamma}{\vartheta}}\left[\int_{\underline{z}}^{\bar{z}} z^{\vartheta} \zeta(d z)\right]^{\frac{\gamma}{\vartheta}} .
$$

Equation (43) implies that the exit threshold does not depend on the equilibrium output price. This result does not hold true if there are positive fixed operating costs. In fact, when there are positive fixed costs, the equilibrium output price has an important feedback effect on the exit threshold and hence on the production and financing decisions, as illustrated in the simulations below. Note that equation (44) implies that the equilibrium output price increases with entry cost. Although it is often argued that the entry cost should not play a role in subsequent price competition, as it is a sunk cost, the present model demonstrates that this sunk cost may feed back into the entry rate and consequently in the output price. In particular, a high entry cost discourages entry and hence protects incumbents. Thus, competition is less intense and the output price becomes higher.

To close this section, I introduce the concept of turnover rate. The turnover rate is an important measure of industry dynamics (see Dunne, Roberts, and Samuelson (1988) and Hopenhayn (1992a)). The turnover rate of entry is defined as the ratio of the mass of entrants to the mass of incumbents. The turnover rate of exit can be defined similarly. Since in a stationary equilibrium the entry rate is equal to the exit rate, these two measures of turnover are equal. Appendix B presents the explicit expressions for the turnover rate as well as other important equilibrium variables. In particular, the formula for 
the turnover rate (B5) implies that the turnover rate is determined exclusively by the exit threshold and the scaled stationary distribution of firms.

\section{Results}

To examine the implications of the model, I first calibrate a base case model. I then conduct simulations based on this model. For all simulations, input parameter values are chosen such that the conditions of Proposition 5 are satisfied.

\section{A. Parameter Values}

The base case model studies the equilibrium with endogenous leverage described in Proposition 6. The parameter values are either taken from the estimated values from the data or chosen such that the model's equilibrium behavior matches some measured statistics as closely as possible. They are used as an illustrative benchmark. Some parameter values can be fine-tuned as in the real business cycle literature (e.g., Kydland and Prescott (1982)).

I first set the fixed operating $\operatorname{cost} c_{f}=0$ so that there is a closed-form solution to the unique equilibrium. I then set the price elasticity of demand $\varepsilon=0.75$. This number is within the range estimated by Phillips (1995).

Next, I calibrate parameters related to technology. Set the returns-to-scale parameter $v=0.40$, as estimated by Caballero and Engel (1999). This implies $\gamma=1 /(1-v)=1.667$. As in the business cycle literature, set the depreciation rate of capital $\delta=0.1$. In order to calibrate the drift $\mu_{z}$ and volatility $\sigma_{z}$, use $\pi\left(z_{t} ; p\right)$ to proxy a firm's cash flow. The growth rate and volatility of cash flows are roughly equal to $2.5 \%$ and $25 \%$, respectively, for a typical Standard \& Poor's 500 firm. Thus, apply Ito's Lemma to equation (3) to derive that $\sigma_{z}=0.25 / \gamma=$ $15 \%$ and $\mu_{z}=\left(0.025-0.5 \gamma(\gamma-1) \sigma_{z}^{2}\right) / \gamma=0.75 \%$

Set the risk-free $r=5.22 \%$ so that it is equal to the average rate on Treasury bills, as reported in Standard \& Poor's The Outlook in 2001. Set the corporate tax rate $\tau=34 \%$, as estimated by Graham (1996). Set the bankruptcy cost parameter $1-\alpha=20 \%$, which is at the upper bound of recent estimates reported in Andrade and Kaplan (1998).

Set the Poisson death parameter $\eta=4 \%$. This number follows from the facts that the annual turnover rate is roughly 7\% (see Dunne et al. (1988) and Hopenhayn (1992b)) and that the default rate is roughly 3\% (see Brady and Bos (2002)).

It remains to calibrate the parameters $c_{e}, \underline{z}$, and $\bar{z}$. First, follow Hopenhayn (1992b) and normalize the equilibrium output price $p^{o}=1$. Next, use equation (42) to determine $c_{e}$ once $\underline{z}$ and $\bar{z}$ are known. Finally, choose values for $\underline{z}$ and $\bar{z}$ so that the following numbers are roughly matched: (i) The average industry Tobin's $q$ is equal to 2.7, which is in the range estimated by Lindenberg and Ross (1981); and, (ii) the turnover rate is $7 \%$.

The base case parameter values are summarized in Table I. 
Table I

Base Case Parameter Values

\begin{tabular}{lcc}
\hline & Parameter & Value \\
\hline Returns to scale & $v$ & 0.40 \\
Depreciation rate & $\delta$ & 0.10 \\
Shock drift & $\mu_{z}$ & $0.75 \%$ \\
Shock volatility & $\sigma_{z}$ & 0.15 \\
Riskless rate & $r$ & $5.22 \%$ \\
Corporate tax rate & $\tau$ & 0.34 \\
Bankruptcy cost & $1-\alpha$ & 0.20 \\
Poisson death & $\eta$ & 0.04 \\
Entry cost & $c_{e}$ & 78.35 \\
Entry distribution & $\underline{z}$ & 2.50 \\
Entry distribution & $\bar{z}$ & 3.50 \\
Price elasticity & $c_{f}$ & 0.75 \\
Fixed cost & & 0.00 \\
\hline
\end{tabular}

\section{B. The Base Case Model}

The equilibrium for the base case model is reported in Panel 1 of Table II. It shows that the average industry leverage ratio is equal to $23.09 \%$. This number is close to the historical average leverage ratio (25\%) reported in Barclay et al. (2002). To compare with the standard single-firm EBIT-based contingent claims model, I adopt the same parameter values for a single risk-neutral firm. The optimal leverage ratio is $71.59 \%$, which is much higher than that typically observed in practice. ${ }^{11}$ The main reason that the present model predicts low leverage is that I compute equilibrium average industry leverage level, instead of a single firm's leverage. In a stationary equilibrium, there are not many surviving firms that have high leverage ratios.

I also compute the industry tax advantage of debt, which is measured as

$$
\frac{\int_{z_{e}^{o}}^{\infty} \frac{b^{o} \tau}{r+\eta}\left[1-\left(z / z_{e}^{o}\right)^{\vartheta}\right] \mu^{o}(d z)}{\int_{z_{e}^{o}}^{\infty} v\left(z, b^{o} ; p^{o}\right) \mu^{o}(d z)} \times 100 \%
$$

The value is $7.08 \%$, which is close to the estimate $(9.7 \%)$ reported in Graham (2000).

Figure 3 plots the stationary distribution of surviving firms. This figure implies that more efficient firms are less likely to exit, since they have higher

\footnotetext{
${ }^{11}$ For a wide range of reasonable parameter values, the Leland-style single-firm contingent claims model typically predicts a much higher leverage ratio than that observed in practice. However, dynamic capital structure models such as Goldstein, Ju, and Leland (2001), Ju et al. (2003), and Hackbarth, Miao, and Morellec (2004) can predict lower leverage ratios. A duopoly model in which firms strategically set their leverage in the run-up to a war of attrition may also generate a low leverage level for at least one of the two firms.
} 


\section{Table II}

\section{Comparative Statics for Selected Parameter Values}

The parameter values for the base case model are given in Table I. Comparative statics is based on the base case model. When performing simulations for the entry cost and demand elasticity, I set the fixed $\operatorname{cost} c_{f}=5$.

\begin{tabular}{|c|c|c|c|c|c|c|c|}
\hline & $\begin{array}{l}\text { Industry } \\
\text { Output }\end{array}$ & $\begin{array}{l}\text { Industry } \\
\text { Price }\end{array}$ & $\begin{array}{c}\text { Average } \\
\text { Leverage (\%) }\end{array}$ & $\begin{array}{l}\text { Turnover } \\
\text { Rate }(\%)\end{array}$ & $\begin{array}{c}\text { Exit } \\
\text { Threshold }\end{array}$ & $\begin{array}{l}\text { Optimal } \\
\text { Coupon }\end{array}$ & $\begin{array}{l}\text { Agency } \\
\text { Cost (\%) }\end{array}$ \\
\hline Base case & 1.00 & 1.00 & 23.09 & 7.51 & 1.91 & 6.66 & 2.57 \\
\hline$\mu_{z}=0.5 \%$ & 0.97 & 1.04 & 28.12 & 7.73 & 1.89 & 6.70 & 3.37 \\
\hline$\mu_{z}=1.0 \%$ & 1.03 & 0.96 & 17.50 & 7.29 & 1.92 & 6.62 & 1.80 \\
\hline$\mu_{z}=1.5 \%$ & 1.10 & 0.88 & 4.46 & 6.91 & 1.94 & 6.55 & 0.39 \\
\hline$\sigma_{z}=10 \%$ & 0.97 & 1.04 & 39.43 & 6.04 & 2.04 & 6.28 & 2.76 \\
\hline$\sigma_{z}=15 \%$ & 1.00 & 1.00 & 23.09 & 7.51 & 1.91 & 6.66 & 2.57 \\
\hline$\sigma_{z}=20 \%$ & 1.06 & 0.92 & 7.04 & 9.13 & 1.79 & 7.18 & 1.08 \\
\hline $\bar{z}=3.5$ & 1.00 & 1.00 & 23.09 & 7.51 & 1.91 & 6.66 & 2.57 \\
\hline $\bar{z}=4.0$ & 1.06 & 0.92 & 22.42 & 7.46 & 2.03 & 6.49 & 2.42 \\
\hline $\bar{z}=4.5$ & 1.12 & 0.86 & 21.68 & 7.40 & 2.15 & 6.30 & 2.25 \\
\hline$\alpha=95 \%$ & 1.01 & 0.998 & 24.50 & 8.27 & 2.02 & 7.20 & 2.51 \\
\hline$\alpha=90 \%$ & 1.006 & 0.992 & 24.00 & 7.98 & 1.98 & 7.01 & 2.54 \\
\hline$\alpha=80 \%$ & 1.00 & 1.00 & 23.09 & 7.51 & 1.91 & 6.66 & 2.57 \\
\hline$\tau=25 \%$ & 1.04 & 0.95 & 20.43 & 7.12 & 1.84 & 5.96 & 1.74 \\
\hline$\tau=34 \%$ & 1.00 & 1.00 & 23.09 & 7.51 & 1.91 & 6.66 & 2.57 \\
\hline$\tau=40 \%$ & 0.97 & 1.04 & 25.00 & 7.70 & 1.94 & 7.08 & 3.22 \\
\hline$c_{f}=5$ & 0.82 & 1.31 & 16.64 & 9.37 & 2.15 & 7.77 & 1.77 \\
\hline$c_{f}=10$ & 0.72 & 1.55 & 13.54 & 10.83 & 2.27 & 8.48 & 1.30 \\
\hline$c_{f}=12$ & 0.69 & 1.64 & 12.68 & 11.35 & 2.30 & 8.76 & 1.17 \\
\hline$c_{e}=70$ & 0.85 & 1.25 & 16.16 & 9.55 & 2.16 & 6.94 & 1.70 \\
\hline$c_{e}=85$ & 0.80 & 1.35 & 16.97 & 9.24 & 2.13 & 8.23 & 1.82 \\
\hline$c_{e}=100$ & 0.76 & 1.44 & 17.61 & 9.01 & 2.11 & 9.52 & 1.92 \\
\hline$\varepsilon=0.60$ & 0.85 & 1.31 & 16.64 & 9.37 & 2.15 & 7.66 & 1.77 \\
\hline$\varepsilon=0.75$ & 0.82 & 1.31 & 16.64 & 9.37 & 2.15 & 7.66 & 1.77 \\
\hline$\varepsilon=0.90$ & 0.79 & 1.31 & 16.64 & 9.37 & 2.15 & 7.66 & 1.77 \\
\hline$\eta=0.03$ & 1.07 & 0.91 & 10.04 & 6.16 & 1.89 & 5.99 & 1.12 \\
\hline$\eta=0.04$ & 1.00 & 1.00 & 23.09 & 7.51 & 1.91 & 6.66 & 2.57 \\
\hline$\eta=0.05$ & 0.94 & 1.08 & 31.35 & 8.80 & 1.92 & 7.33 & 3.46 \\
\hline
\end{tabular}

technology (productivity) levels that are farther away from the exit threshold. This prediction is consistent with the empirical finding reported by Kovenock and Phillips (1997). Since the size of a firm measured by either output $y(z, p)$ or input $k(z, p)$ is an increasing function of its technology shock $z$, the long-run size (probability) distribution plotted in Figure 4 has a similar shape to that plotted in Figure 3. Note that the size distribution does not depend on firm age. The issue of size and age dependence is studied by Cooley and Quadrini (2001).

Another property of the base case model is that although all firms in the industry are ex ante identical, and hence pay the same coupon amount, the 


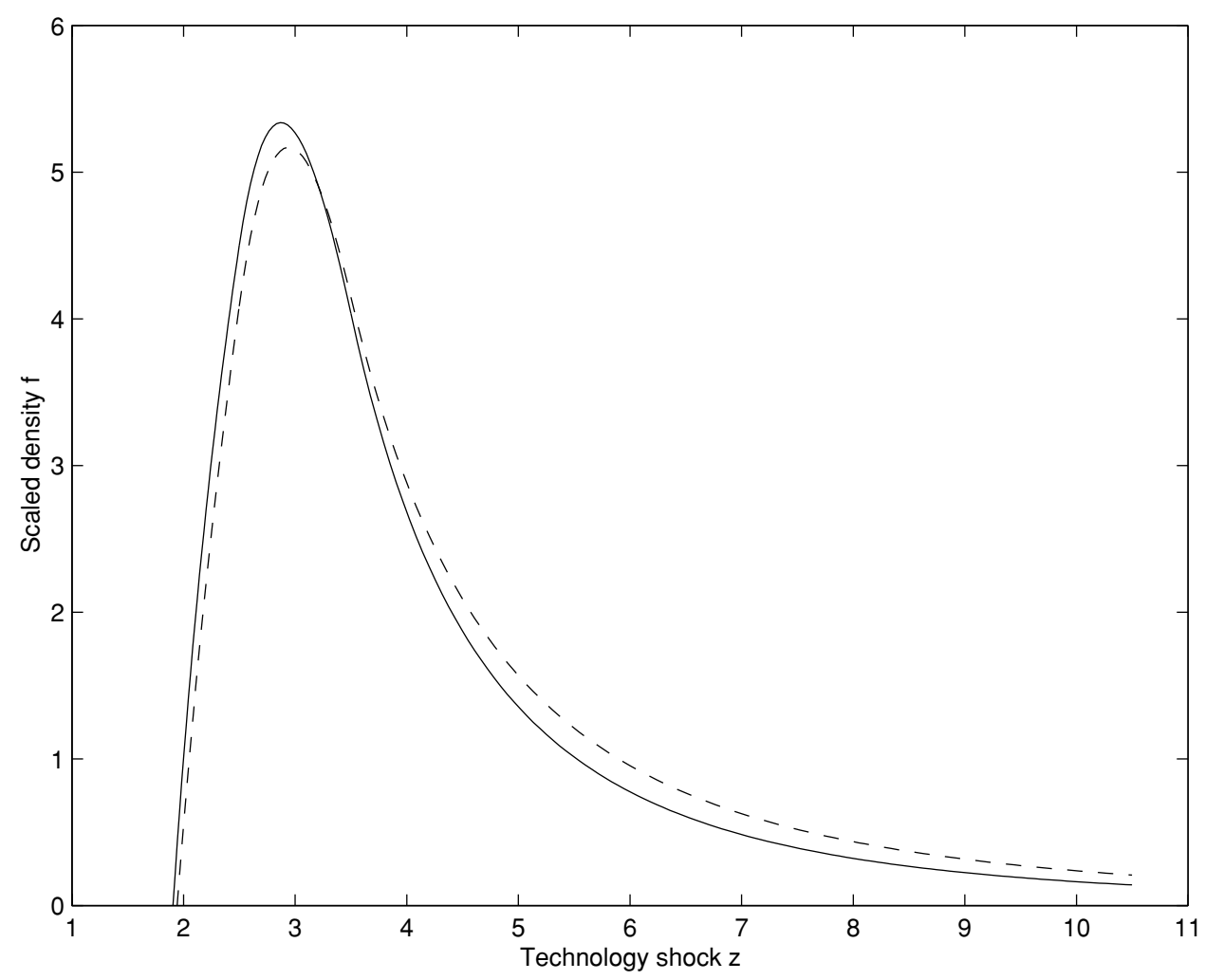

Figure 3. The effect of an increase in growth of technology on the scaled density of firms. The solid line is for the base case model. The dashed line is for $\mu_{z}=1.5 \%$. All other parameter values are given in Table I.

leverage ratios vary across firms. In particular, small or inefficient firms take on high leverage. This is because surviving firms differ in realizations of technology shocks so that they have different equity values. ${ }^{12}$ This result is related to the empirical finding of Welch (2004) that leverage changes are mainly determined by equity returns.

Simulations reported in Table II also reveal that the average industry agency cost accounts for $2.57 \%$ of the first-best average industry firm value. In later simulations, I find that the magnitude of the average industry agency cost is approximately $2 \%$ for a wide range of parameter values. Thus, the agency costs arising from the conflict of interest between shareholders and bondholders are quite small. A similar finding is reported in Parrino and Weisbach (1999). The present model implies that competition can mitigate the bondholder-shareholder agency problem. This is because inefficient firms have

\footnotetext{
${ }^{12}$ Maksimovic and Zechner (1991) attribute the variation of capital structures to the adoption of different technologies within the industry.
} 


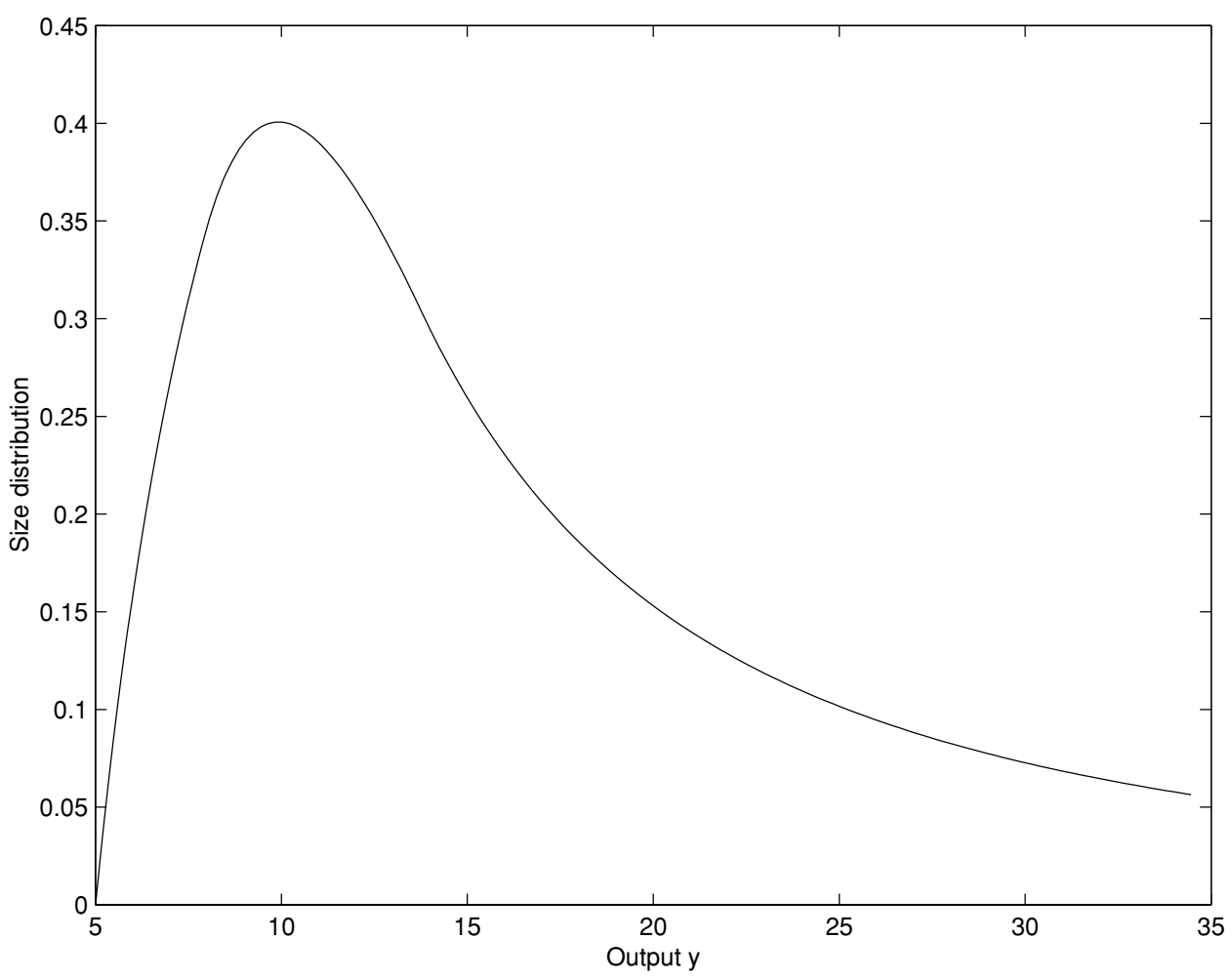

Figure 4. The size distribution of firms. This figure plots the size distribution of firms measured according to output. This distribution is derived from the scaled density of the equilibrium stationary distribution. The parameter values are given in Table I.

high agency costs as discussed in Section II.E, but they cannot survive in an industry equilibrium.

To compare with Hopenhayn's (1992a) industry dynamics model without debt financing, I set the fixed operating cost $c_{f}=5$ and compute equilibria with and without debt financing. The equilibrium outcome for the model with debt financing is reported in the 12 th row of Table II. By contrast, when firms do not take into account tax advantages of debt and are all-equity financed, industry output is 0.72 , the turnover rate is $4.77 \%$, and average industry firm value is 372.12 , all of which are lower than the model with debt financing. Thus, debt financing not only raises firm value, ${ }^{13}$ but also facilitates efficient exit and increases industry output. The intuition is simple. Debt increases the exit threshold (see equations (26) and (30)), and hence induces inefficient firms to exit. In addition, increased firm value promotes entry. Competition then drives down the output price and raises industry output.

\footnotetext{
${ }^{13}$ Average industry firm value is 395.57 in the present model. This number is not reported in
} Table II. 


\section{Comparative Statics}

Since capital structure and production decisions may simultaneously respond to changes in exogenous factors, I focus on the stationary equilibrium with optimal leverage described in Section III.B and examine comparative static properties of the equilibrium based on the base case model studied earlier.

\section{C.1. Technology Growth and Entry Distribution}

Panel 2 of Table II details the effect of changes in technology growth. As argued in the introduction, the standard single-firm tradeoff model cannot explain the empirical evidence that high growth firms have low leverage. However, in the present industry equilibrium framework, the tradeoff theory can still explain this fact. This is because the price feedback effect discussed in the introduction plays an important role. Simulations reported in Table II show that this effect dominates so that the optimal coupon rate falls and the liquidation threshold rises with technology growth $\mu_{z}$. Simulations also reveal that the tax benefit of debt falls and average industry leverage falls with $\mu_{z}$.

Since the market-to-book ratio is positively related to technology growth, ${ }^{14}$ it is negatively related to leverage. The usual interpretation of this fact is based on the underinvestment problem of debt identified by Myers (1977) or the free cash flow theory of Jensen (1986). Two recent interpretations are offered by Welch (2004) and Baker and Wurgler (2002). The present model, however, offers a new interpretation in an industry equilibrium setting.

To examine why the price feedback effect may dominate and how robust the result is, consider the expression for the before-tax present value of profits (25),

$$
\Pi(z ; p)=\frac{p^{\gamma}(1-v)\left(\frac{v}{r /(1-\tau)+\delta}\right)^{v \gamma}}{r+\eta-\mu_{z} \gamma-\sigma_{z}^{2} \gamma(\gamma-1) / 2} z^{\gamma}-\frac{c_{f}}{r+\eta},
$$

where I have substituted the expressions for $a(p)$ and $\lambda$ in (8) and (22). If $\Pi(z$; $p$ ) is price elastic (i.e., $\gamma>1$ ), and if the level and changes of the growth rate $\mu_{z}$ are small, then the decrease in the price $p$ may well dominate the increase in $\mu_{z}$. In the present model, under decreasing-returns-to-scale technology $v<$ $1, \gamma \equiv 1 /(1-v)$ must be bigger than 1 . Moreover, for a typical firm the growth rate of cash flows and its change are unlikely to be high. Therefore, I conclude that the result is quite robust for a wide range of reasonable parameter values.

The increase in $\mu_{z}$ also has a positive selection effect because it changes the liquidation threshold and the stationary distribution of firms. Figure 3 illustrates that this effect causes the scaled density function to shift to the right. Thus, to survive in the industry, firms must have high productivity or technology levels. This makes entry tougher. Thus, the turnover rate decreases.

\footnotetext{
${ }^{14}$ Simulations (not reported in Table II) confirm this positive correlation. The market-to-book ratio is a commonly used proxy for growth opportunities.
} 
Note that even though the increase in technology growth may cut the present value of profits, the average industry equity value and firm value rise with technology growth. Simulations show that when $\mu_{z}$ increases from $0.75 \%$ to $1.5 \%$, average industry equity value increases from 203.57 to 1338.2 and average industry firm value increases from 264.68 to 1400.8 . This is because those values are computed using the stationary distribution of surviving firms. In addition, the positive selection effect implies that a high growth industry has a greater number of highly efficient firms than a low growth industry. These highly efficient firms have higher equity value and firm value. Furthermore, simulations show that the size of the high growth industry is much lower than that of the low growth industry.

The impact of an improvement of the entry distribution (i.e., an increase in $\bar{z})$ is similar to that of an increase in technology growth, as reported in Panel 4 of Table II. So I omit the discussion.

\section{C.2. Riskiness of Technology}

Panel 3 of Table II documents the effect of changes in technology volatility. As in the standard contingent claims model, the volatility parameter $\sigma_{z}$ provides a measure of bankruptcy risk and hence is an important determinant of leverage. Panel 3 of Table II reveals that volatility is negatively related to average industry leverage. This prediction is similar to that in the single-firm model and is consistent with the empirical evidence documented by Titman and Wessels (1988).

Panel 3 of Table II also reveals that volatility is positively related to industry output. This is because an increase in $\sigma_{z}$ has an option effect in that it raises the option value of waiting to default. This results in higher firm value and hence encourages entry. Competition then drives down the output price and raises industry output. Finally, Panel 3 of Table II reveals that an increase in volatility has a positive selection effect, resulting in a high turnover rate.

\section{C.3. Bankruptcy Cost and Corporate Tax}

Panel 5 of Table II reports the effect of changes in the bankruptcy cost. An increase in the bankruptcy cost parameter $1-\alpha$ has a negative cash flow effect. This effect decreases the value of an active firm and depresses entry. As a result, the output price rises and industry output falls.

While it is intuitive that bankruptcy costs are negatively related to leverage, Panel 5 of Table II also reveals that bankruptcy costs are negatively related to the turnover rate. The intuition is that an increase in the bankruptcy cost lowers debt and hence decreases the opportunity cost of remaining active. Thus, each incumbent prefers to stay longer in the industry. Consequently, the liquidation threshold falls. The lower value of the liquidation threshold implies less selection and higher expected lifetime of firms. As a result, the turnover rate falls. 
An increase in the corporate tax rate has the same negative cash flow effect as an increase in the bankruptcy cost so that industry output falls with the tax rate. However, the increase in the corporate tax rate raises the tax benefit of debt and hence has an opposite effect on leverage and turnover relative to an increase in the bankruptcy cost. The impact of the tax rate is reported in Panel 6 of Table II. I omit the detailed analysis.

\section{C.4. Fixed Operating Cost}

So far, I have set the fixed operating $\operatorname{cost} c_{f}$ to zero. Because the fixed cost is related to the degree of economies of scale, I now examine the impact of the fixed operating cost on equilibrium outcomes, as reported in Panel 7 of Table II. ${ }^{15}$

The panel reveals that the fixed cost is positively related to the turnover rate, and negatively related to industry output and leverage. The intuition is as follows. An increase in the fixed operating cost lowers the operating profit and hence lowers firm value. This depresses entry, raises the output price, and hence lowers industry output. As reported in Panel 7 of Table II, the positive price feedback effect is dominated so that each incumbent prefers to exit earlier, resulting in an increased exit threshold and an increased turnover rate.

I now analyze the impact on leverage. While the increased fixed cost lowers the tax benefit of debt, it also lowers unlevered firm value and hence bankruptcy costs. Simulations reported in Panel 7 of Table II reveal that the latter effect dominates so that the optimal coupon rises. Thus, the average industry value of debt also rises. However, due to the positive selection and price effects, average industry firm value also increases with the fixed cost. The intuition is that following an increase in the fixed cost, surviving firms are more efficient since the exit threshold is higher and the positive price effect is stronger for those firms. A similar result is derived in Hopenhayn (1992a, 1992b) for all-equity financed firms. Simulations reported in Panel 7 of Table II show that the increase in firm value dominates the increase in debt value so that average industry leverage falls with the fixed cost.

\section{C.5. Entry Cost}

In the short run, an increase in the entry $\operatorname{cost} c_{e}$ does not affect a firm's cash flows and its liquidation decision. Thus, it does not affect the value of an active firm. However, the entry cost acts as a barrier to entry. High entry costs protect incumbents and drive up the industry output price. This price feedback effect will generally influence financing and exit decisions.

Specifically, the increase in the output price raises the benefit of remaining active and the tax advantage of debt. On the other hand, this implies that each firm prefers to issue more debt and hence the optimal coupon rises. This leads to an increased opportunity cost of remaining active. The

\footnotetext{
${ }^{15}$ As a robustness check, I redo all previous simulations for a number of positive values of the entry cost. I find the results do not change qualitatively.
} 
impact on the exit threshold depends on these two opposite effects as shown in equation (31). When there is no fixed operating cost, these effects offset each other so that changes in the entry cost do not affect the exit threshold (see equation (43)). Consequently, these changes do not have a selection effect.

However, this result is not robust to the introduction of the fixed operating cost. To illustrate this point, I set the operating cost $c_{f}=5$. Panel 8 of Table II documents the impact of increases in the entry cost. It reveals that the entry cost is positively related to leverage and negatively related to the turnover rate. ${ }^{16}$ This is because in response to an increase in the entry cost, the positive price feedback effect dominates so that the exit threshold decreases. This results in a negative selection effect so that the turnover rate falls. This prediction is consistent with the evidence reported by Orr (1974) for Canadian industry. A similar result is derived by Hopenhayn (1992a) for all-equity financed firms. In the present model, a lower exit threshold also induces lower default/exit probabilities, and hence expected bankruptcy costs are lower. This results in higher leverage.

\section{C.6. Industry Demand Elasticity}

I now analyze the impact of changes in demand elasticity, which is an important industry characteristic. From Proposition 6, one finds surprisingly that the output price $p^{o}$, the exit threshold $z_{e}^{o}$, and the scaled density $f^{o}$ do not depend on the demand elasticity parameter $\varepsilon$. Consequently, the turnover rate and average industry leverage do not depend on $\varepsilon$. However, the change in demand elasticity does have on effect an industry output, industry size, and entry rate. As can be seen from Appendix B, this result is also true for positive fixed costs $c_{f}>0$. The key intuition is that the competitive entry condition (15), which determines the equilibrium output price, is independent of the industry demand elasticity. This implies that the industry output price is also independent of the demand elasticity. Consequently, the exit threshold is independent of the demand elasticity since it is determined by an individual firm's behavior taking industry prices as given. Since the scaled stationary distribution is determined by the exit threshold and the exogenous evolution of the technology process, it is also independent of the demand elasticity.

To illustrate the above result, I set $c_{f}=5$ and fix other parameter values as in Table I. Panel 9 of Table II illustrates the effect of increases in the demand elasticity. I find that the industry output, industry size, and entry rate all decrease. This is because the isoelastic demand function (1) implies that the industry output decreases with the demand elasticity for any fixed price $p>1$. To accommodate decreased industry output, the entry rate and industry size must fall.

\footnotetext{
${ }^{16}$ This result does not depend on the choice of $c_{f}=5$ since it is verified by simulations for many other values of $c_{f}$.
} 


\section{C.7. Poisson Deaths}

As discussed earlier, a sufficiently high Poisson death rate is needed for the existence of a stationary equilibrium in the present model. I now examine the impact of changes in this rate, as detailed in the last panel of Table II. As expected, increased death rates lower industry output. Surprisingly, firms issue more debt and average industry leverage increases. This is because an incumbent enjoys high output price and hence high tax benefits of debt (see equation (36)). Consider next the turnover rate. In order for the population of firms to keep being refreshed, the turnover rate of entry must rise in response to an increased Poisson death rate. Surprisingly, the turnover rate of exit due to bankruptcy also rises, which is the difference between the turnover rate of entry and the Poisson death rate. ${ }^{17}$ This is because the exit threshold rises following an increase in the Poisson death rate. Thus, firms are more likely to go bankrupt and exit.

\section{Conclusion}

In this paper, I present a competitive equilibrium model of industry dynamics and capital structure decisions. I show that technology (productivity) heterogeneity is important in determining a firm's survival probability and leverage ratio. In particular, in equilibrium there is a stationary distribution of surviving firms. These firms exhibit a wide variation of capital structures. In addition, more efficient firms are less likely to exit and have lower agency costs. Finally, I analyze comparative static properties of changes in technology growth, technology risk, entry distribution, entry cost, fixed cost, bankruptcy cost, and tax policy.

The analysis reveals that the interaction between financing and production decisions is important in an industry equilibrium. Moreover, the equilibrium output price has an important feedback effect. As a result, several conclusions reached in the standard single-firm contingent claims models do not hold true in an equilibrium setting. Moreover, it moves predictions in the right direction in terms of reconciling the empirical evidence. Specifically, the analysis shows that either one of the following exogenous factors can simultaneously explain the empirical findings mentioned in the introduction: the slowdown of technology (productivity) growth, the deterioration of entry distribution, or the increase in the corporate tax rate.

The paper also provides a number of new testable predictions regarding capital structure and industry dynamics. First, industries with high technology growth or good starting distributions of technology have relatively lower average leverage, lower turnover rates, and higher output. Second, industries with risky technology have relatively lower average leverage, higher turnover rates, and higher output. Third, industries with high bankruptcy costs have relatively lower average leverage, lower turnover rates, and lower output. Fourth,

\footnotetext{
${ }^{17}$ This rate is given by $3.16,3.51$, and 3.80 for $\eta$ equal to $0.03,0.04$, and 0.05 , respectively.
} 
industries with high fixed operating costs have relatively lower average leverage, higher turnover rates, and lower output. Finally, industries with high entry costs have relatively higher average leverage, lower turnover rates, and lower output.

The paper could be extended in several directions, which are left for future research. First, in the paper, the expected returns of equity and other macroeconomic variables are constant. To study equity premium and other time-series behavior of the industry, it is necessary to introduce aggregate uncertainty. Second, this paper considers only the conflict of interest between shareholders and bondholders. It would be interesting to study the conflict of interest between shareholders and managers. Third, I analyze firms' initial capital structure decisions only, as in most contingent claims models of capital structure in the literature. A model of dynamic capital structure would be worth pursuing (Leland (1998), Goldstein, Ju, and Leland (2001), Ju et al. (2003), and Hackbarth, Miao, and Morellec (2004)). Finally, it would be interesting to consider finite maturity debt. This requires a constant default threshold in stationary equilibrium, which can be delivered using the framework of Leland and Toft (1996) or Leland (1998).

\section{Appendix A. Proofs}

Proof of Propositions 1-2: ${ }^{18}$ I first prove Proposition 2. Proposition 1 is obtained by setting $b=0$. It follows from (27) that equity value given a default threshold $y$ is given by

$$
e(z, b ; p \mid y)=(1-\tau) E^{z}\left[\int_{0}^{T_{y}} e^{-(r+\eta) t}\left(\pi\left(z_{t} ; p\right)-b\right) d t\right] .
$$

This expression is equal to

$$
\begin{aligned}
& (1-\tau) E^{z}\left[\int_{0}^{\infty} e^{-(r+\eta) t}\left(\pi\left(z_{t} ; p\right)-b\right) d t\right]-(1-\tau) E^{z} \\
& \quad \times\left[\int_{T_{y}}^{\infty} e^{-(r+\eta) t}\left(\pi\left(z_{t} ; p\right)-b\right) d t\right]=(1-\tau) E^{z}\left[\int_{0}^{\infty} e^{-(r+\eta) t}\left(\pi\left(z_{t} ; p\right)-b\right) d t\right] \\
& \quad-(1-\tau) E^{y}\left[\int_{0}^{\infty} e^{-(r+\eta) t}\left(\pi\left(z_{t} ; p\right)-b\right) d t\right] \times E^{z}\left[e^{-(r+\eta) T_{y}}\right]
\end{aligned}
$$

where the last equality follows from the strong Markov property of the process $\left(z_{t}\right)_{t \geq 0}$ (see Karatzas and Shreve (1991, p. 82)). By an argument similar to that in Karatzas and Shreve (1991, p. 197),

$$
E^{z}\left[e^{-(r+\eta) T_{y}}\right]=\left(\frac{z}{y}\right)^{\vartheta}
$$

\footnotetext{
${ }^{18}$ Here I use a probabilistic proof method similar to Mella-Barral (1995) and Morellec (2004). An alternative standard method is to use ODEs (e.g., Leland (1994)).
} 
where $\vartheta$ is given in (24). Substitute this expression into above equations to derive

$$
e(z, b ; p \mid y)=(1-\tau)\left[\Pi(z ; p)-\frac{b}{r+\eta}+\left(\frac{b}{r+\eta}-\Pi(y ; p)\right)\left(\frac{z}{y}\right)^{\vartheta}\right] .
$$

Use the smooth-pasting condition (28) to derive the optimal default threshold $z_{d}(b ; p)$ in $(30)$. Use the fact that $e(z, b ; p)=e\left(z, b ; p \mid z_{d}\right)$ to derive equity value in (29). Q.E.D.

Proof of Proposition 3: As in the proof of Propositions 1-2, one can use (13) and the strong Markov property to derive

$$
\begin{aligned}
& d(z, b ; p) \\
& \quad=E^{z}\left[\int_{0}^{T_{z_{d}}} e^{-(r+\eta) t} b d t\right]+\alpha A\left(z_{d} ; p\right) E^{z}\left[e^{-(r+\eta) T_{z_{d}}}\right] \\
& \quad=E^{z}\left[\int_{0}^{\infty} e^{-(r+\eta) t} b d t\right]-E^{z}\left[\int_{T_{z_{d}}}^{\infty} e^{-(r+\eta) t} b d t\right]+\alpha A\left(z_{d} ; p\right) E^{z}\left[e^{-(r+\eta) T_{z_{d}}}\right] \\
& =\frac{b}{r+\eta}-E^{z}\left[\int_{0}^{\infty} e^{-(r+\eta) t} b d t\right] E^{z}\left[e^{-(r+\eta) T_{z_{d}}}\right]+\alpha A\left(z_{d} ; p\right) E^{z}\left[e^{-(r+\eta) T_{z_{d}}}\right] \\
& =\frac{b}{r+\eta}+\left(\alpha A\left(z_{d} ; p\right)-\frac{b}{r+\eta}\right) E^{z}\left[e^{-(r+\eta) T_{z_{d}}}\right] .
\end{aligned}
$$

Use the last expression and (A3) to obtain (32). Finally, one can derive firm value in (33) by using equations (13), (29), and (32). Q.E.D.

Proof of Proposition 4: Similar to the derivation of equation (33), one can deduce that firm value given a default threshold $y$ is given by

$$
v(z, b ; p \mid y)=A(z ; p)+\frac{b \tau}{r+\eta}\left[1-\left(\frac{z}{y}\right)^{\vartheta}\right]-(1-\alpha) A(y ; p)\left(\frac{z}{y}\right)^{\vartheta} .
$$

The first-best liquidation policy is to choose default threshold $y$ so as to maximize firm value in (A6). It can be verified that the maximizer is $z_{d}^{F B}=z_{A}$. Equation (37) follows from the fact that $v^{F B}(z, b ; p)=v\left(z, b ; p \mid z_{A}\right)$. Finally, equation (38) follows from $c_{A}(z, b ; p)=v^{F B}(z, b ; p)-v(z, b ; p)$. Q.E.D.

Proof of Proposition 5: As argued in Section III.A, the proof consists of three steps. In the first step, one uses the entry condition to solve for the equilibrium output price $p^{*}$. Then the exit threshold $z_{e}$ is determined by $z_{e}=z_{d}\left(z, b ; p^{*}\right)$ using equation (30). In the second step, one solves for the density $f$ of the stationary distribution $\mu^{*}$ up to a scale factor $N^{*}$. In the final step, the entry rate $N^{*}$ is determined by the market-clearing condition (18). Specifically, use (5) and (16) to derive the industry output 


$$
Y\left(\mu^{*}, b ; p^{*}\right)=N^{*} \int_{z_{e}}^{\infty} z^{\gamma} f(z) d z\left(\frac{p v}{r /(1-\tau)+\delta}\right)^{v \gamma} .
$$

Use the market-clearing condition $p^{*}=Y\left(\mu^{*}, b ; p^{*}\right)^{-1 / \varepsilon}$ to derive the entry rate

$$
N^{*}=\left(p^{*}\right)^{-(\varepsilon+\gamma \nu)}\left(\int_{z_{e}}^{\infty} z^{\gamma} f(z) d z\right)^{-1}\left(\frac{v}{r /(1-\tau)+\delta}\right)^{-v \gamma} .
$$

Note that the integral $\int_{z_{e}}^{\infty} z^{\gamma} f(z) d z$ is improper since the density $f$ has an infinite support. Once $f$ is derived toward the end of the proof, one will see that assumption (40) ensures that this improper integral is finite.

The remainder of the proof is devoted to the second step, which is key. It is convenient to work in terms of the $\operatorname{logarithm}, x=\log z$. Then $\left(x_{t}\right)_{t \geq 0}$ is a Brownian motion satisfying,

$$
d x_{t}=\mu_{x} d t+\sigma_{x} d W_{t}
$$

where $\mu_{x}=\mu_{z}-\frac{1}{2} \sigma_{z}^{2}$ and $\sigma_{x}=\sigma_{z}$. Because the initial draw of $z$ is uniform over $[\underline{z}, \bar{z}]$, the initial draw of $x=\log (z)$ has an exponential distribution over $[\underline{x}, \bar{x}]$, where $\bar{x}=\log \bar{z}$ and $\underline{x}=\log \underline{z}$. This distribution has a density function

$$
g(x)=\exp (x-\hat{x})
$$

where $\hat{x}=\log (\bar{z}-\underline{z})$.

Let the stationary distribution of incumbent firms have a density function $N^{*} \phi(x)$ on $\left[x_{e}, \infty\right)$, where $x_{e}=\log \left(z_{e}\right)$ and $N^{*}$ is the entry rate determined later. I will now use the Kolmogorov equation to find the function $\phi(x)$ by considering three cases.

I adapt the heuristic argument from Dixit and Pindyck (1994, Chapter 8). First, approximate the Brownian motion by a random walk. To do so, divide time into short intervals of duration $d t$, and the $x$ space into short segments, each of length $d h=\sigma_{x} \sqrt{d t}$. Of the firms located in one such segment, during time $d t$ a proportion $\eta d t$ will die. Of the rest, a fraction $q_{r}$ will move one segment to the right, and a fraction $q_{l}$ will move to the left, where

$$
q_{r}=\frac{1}{2}\left[1+\frac{\mu_{x}}{\sigma_{x}} \sqrt{d t}\right], \quad q_{l}=\frac{1}{2}\left[1-\frac{\mu_{x}}{\sigma_{x}} \sqrt{d t}\right] .
$$

Now consider the first case, where $\underline{x} \leq x<\bar{x}$. Then there are new entrants that realize shock $x$ since the support of their initial draw of shocks is $[\underline{x}, \bar{x}]$. There are $N^{*} \phi(x) d h$ firms in the segment centered at $x$. In the next unit of time period $d t$, all of these firms move away with either Poisson or Brownian shocks. New entrants, as well as firms from the left and right, arrive to take their places. For balance,

$$
\begin{aligned}
N^{*} \phi(x) d h= & N^{*} d \operatorname{tg}(x) d h+q_{r}(1-\eta d t) N^{*} \phi(x-d h) d h \\
& +q_{l}(1-\eta d t) N^{*} \phi(x+d h) d h .
\end{aligned}
$$


Apply Taylor's expansion theorem and simplify to obtain the ODE

$$
\frac{1}{2} \sigma_{x}^{2} \phi^{\prime \prime}(x)-\mu_{x} \phi^{\prime}(x)-\eta \phi(x)+g(x)=0 .
$$

A particular solution to this equation can be derived as

$$
\phi_{0}(x)=e^{x-\hat{x}} /\left(\eta+\mu_{x}-\sigma_{x}^{2} / 2\right) .
$$

To make economic sense, this density must be positive (also see Dixit and Pindyck (1994, p. 275)). This is ensured by assumption (41) since $\eta+\mu_{x}-$ $\sigma_{x}^{2} / 2=\eta+\mu_{z}-\sigma_{z}^{2}>0$. The general solution to (A13) is given by

$$
\phi(x)=A_{1} e^{\beta_{1} x}+A_{2} e^{\beta_{2} x}+\phi_{0}(x), \quad \text { for } \underline{x} \leq x<\bar{x},
$$

where

$$
\beta_{1}=\frac{\mu_{x}-\sqrt{\mu_{x}^{2}+2 \sigma_{x}^{2} \eta}}{\sigma_{x}^{2}}, \quad \beta_{2}=\frac{\mu_{x}+\sqrt{\mu_{x}^{2}+2 \sigma_{x}^{2} \eta}}{\sigma_{x}^{2}}
$$

and $A_{1}$ and $A_{2}$ are constants to be determined.

In the second case, $x_{e}<x<\underline{x}$, there is no new entrant in the segment centered at $x$. Apply a similar method to show that $\phi$ satisfies the following ODE:

$$
\frac{1}{2} \sigma_{x}^{2} \phi^{\prime \prime}(x)-\mu_{x} \phi^{\prime}(x)-\eta \phi(x)=0 .
$$

The general solution to this equation is given by

$$
\phi(x)=G_{1} e^{\beta_{1} x}+G_{2} e^{\beta_{2} x}, \quad \text { for } x_{e}<x<\underline{x},
$$

where $G_{1}$ and $G_{2}$ are constants to be determined.

In the third case, $x \geq \bar{x}$, there is no new entrant in the segment centered at $x$, so $\phi$ still satisfies the above ODE. Let the solution be

$$
\phi(x)=H_{1} e^{\beta_{1} x}+H_{2} e^{\beta_{2} x}, \quad \text { for } x \geq \bar{x},
$$

where $H_{1}$ and $H_{2}$ are constants to be determined.

The constants $A_{1}, A_{2}, G_{1}, G_{2}, H_{1}$, and $H_{2}$ are determined by the following six boundary conditions:

$$
\begin{aligned}
\int_{\bar{x}}^{\infty} \phi(x) d x & <\infty, \\
\phi\left(x_{e}\right) & =0, \\
\lim _{x \uparrow \underline{x}} \phi(x) & =\lim _{x \downarrow \underline{x}} \phi(x), \\
\lim _{x \uparrow \underline{x}} \phi^{\prime}(x) & =\lim _{x \downarrow \underline{x}} \phi^{\prime}(x), \\
\lim _{x \uparrow \bar{x}} \phi(x) & =\lim _{x \downarrow \bar{x}} \phi(x),
\end{aligned}
$$




$$
\lim _{x \uparrow \bar{x}} \phi^{\prime}(x)=\lim _{x \downarrow \bar{x}} \phi^{\prime}(x) .
$$

Equation (A20) says that the total mass of incumbents must be finite. Equation (A21) is derived from the fact that when the process $\left(x_{t}\right)$ falls to $x_{e}$, the firm exits the industry. Finally, equations (A22)-(A25) follow from Theorem 4.4.9 in Karatzas and Shreve (1991, p. 271). These equations ensure sufficient smoothness of $\phi$. Using equations (A20)-(A25), one can derive $\mathrm{H}_{2}=0$ and $G_{1}, G_{2}, A_{1}, A_{2}, H_{1}$ solve the following system of linear equations:

$$
\begin{aligned}
G_{1} e^{\beta_{1} x_{e}}+G_{2} e^{\beta_{2} x_{e}} & =0 \\
G_{1} e^{\beta_{1} \underline{x}}+G_{2} e^{\beta_{2} \underline{x}} & =A_{1} e^{\beta_{1} \underline{x}}+A_{2} e^{\beta_{2} \underline{x}}+\phi_{0}(\underline{x}), \\
G_{1} \beta_{1} e^{\beta_{1} \underline{x}}+G_{2} \beta_{2} e^{\beta_{2} \underline{x}} & =A_{1} \beta_{1} e^{\beta_{1} \underline{x}}+A_{2} \beta_{2} e^{\beta_{2} \underline{x}}+\phi_{0}^{\prime}(\underline{x}), \\
A_{1} e^{\beta_{1} \bar{x}}+A_{2} e^{\beta_{2} \bar{x}}+\phi_{0}(\bar{x}) & =H_{1} e^{\beta_{1} \bar{x}} \\
A_{1} \beta_{1} e^{\beta_{1} \bar{x}}+A_{2} \beta_{2} e^{\beta_{2} \bar{x}}+\phi_{0}^{\prime}(\bar{x}) & =H_{1} \beta_{1} e^{\beta_{1} \bar{x}} .
\end{aligned}
$$

The solution in terms of $z$ is

$$
\begin{aligned}
& A_{1}=\frac{\left(1-\beta_{1}\right) z_{e}^{\beta_{2}-\beta_{1}}\left(\bar{z}^{1-\beta_{2}}-\underline{z}^{1-\beta_{2}}\right)+\left(1-\beta_{2}\right) \underline{z}^{1-\beta_{1}}}{\left(\beta_{2}-\beta_{1}\right)(\bar{z}-\underline{z})\left(\eta+\mu_{z}-\sigma_{z}^{2}\right)}, \\
& A_{2}=-\frac{\left(1-\beta_{1}\right) \bar{z}^{1-\beta_{2}}}{\left(\beta_{2}-\beta_{1}\right)(\bar{z}-\underline{z})\left(\eta+\mu_{z}-\sigma_{z}^{2}\right)}, \\
& G_{1}=\frac{\left(1-\beta_{1}\right) z_{e}^{\beta_{2}-\beta_{1}}\left(\bar{z}^{1-\beta_{2}}-\underline{z}^{1-\beta_{2}}\right)}{\left(\beta_{2}-\beta_{1}\right)(\bar{z}-\underline{z})\left(\eta+\mu_{z}-\sigma_{z}^{2}\right)}, \\
& G_{2}= \frac{\left(1-\beta_{1}\right)\left(\underline{z}^{1-\beta_{2}}-\bar{z}^{1-\beta_{2}}\right)}{\left(\beta_{2}-\beta_{1}\right)(\bar{z}-\underline{z})\left(\eta+\mu_{z}-\sigma_{z}^{2}\right)}, \\
& H_{1}=\frac{\left(1-\beta_{1}\right) z_{e}^{\beta_{2}-\beta_{1}}\left(\bar{z}^{1-\beta_{2}}-\underline{z}^{1-\beta_{2}}\right)+\left(\beta_{2}-1\right)\left(\bar{z}^{1-\beta_{1}}-\underline{z}^{1-\beta_{1}}\right)}{\left(\beta_{2}-\beta_{1}\right)(\bar{z}-\underline{z})\left(\eta+\mu_{z}-\sigma_{z}^{2}\right)} .
\end{aligned}
$$

In terms of $z$, the density function of $\mu^{*}$ is given by $N^{*} f(z)=\frac{N^{*}}{z} \phi(\log (z))$, where

$$
f(z)= \begin{cases}G_{1} z^{\beta_{1}-1}+G_{2} z^{\beta_{2}-1}, & \text { for } z_{e}<z \leq \underline{z}, \\ A_{1} z^{\beta_{1}-1}+A_{2} z^{\beta_{2}-1}+\frac{1}{(\bar{z}-\underline{z})\left(\eta+\mu_{z}-\sigma_{z}^{2}\right)}, & \text { for } \underline{z}<z \leq \bar{z}, \\ H_{1} z^{\beta_{1}-1}, & \text { for } z>\bar{z} .\end{cases}
$$

I finally show that assumption (40) ensures $\int_{z_{e}}^{\infty} z^{\gamma} f(z) d z$ is finite. It suffices to show that $\int_{\bar{z}}^{\infty} z^{\gamma} f(z) d z$ is finite. Since $f(z)=H_{1} z^{\beta_{1}-1}$ for $z>\bar{z}$,

$$
\int_{\bar{z}}^{\infty} z^{\gamma} f(z) d z=H_{1} \int_{\bar{z}}^{\infty} z^{\beta_{1}+\gamma-1} f(z) d z=\frac{H_{1}}{\beta_{1}+\gamma}\left(\lim _{z \rightarrow \infty} z^{\beta_{1}+\gamma}-\bar{z}^{\beta_{1}+\gamma}\right) .
$$


Thus, if and only if $\beta_{1}+\gamma<0$ is satisfied, $\lim _{z \rightarrow \infty} z^{\beta_{1}+\gamma}=0$ and the above integral is finite. By (A16), the condition $\beta_{1}+\gamma<0$ is equivalent to assumption (40).

Q.E.D.

Proof of Proposition 6: The analysis in Section II.D shows that when $c_{f}=0$, for any output price $p$ the optimal coupon rate $b^{*}(p)$ is given by (36). Since $c_{f}=0$, it follows from (31) that the exit threshold is given by

$$
z_{d}(b ; p)=\left[\frac{\vartheta \lambda b}{(\vartheta-\gamma)(r+\eta) a(p)}\right]^{1 / \gamma}
$$

Substituting (36) for $b$ into this expression yields

$$
z_{d}\left(b^{*}(p) ; p\right)=\left[\frac{\gamma-\vartheta}{\gamma}-\frac{\vartheta(1-\alpha)(1-\tau)}{\gamma \tau}\right]^{\frac{1}{\vartheta}}\left[\int_{\underline{z}}^{\bar{z}} z^{\vartheta} \zeta(d z)\right]^{\frac{1}{\vartheta}}
$$

Since this expression is independent of the output price, it is also the equilibrium exit threshold $z_{e}^{o}$ given in (43). I now derive the equilibrium output price using the entry condition (42). Substituting (33), (36), and (43) into (42), one can solve for the unique equilibrium output price $p^{\circ}$ given in (44). Finally, the equilibrium entry rate $N^{o}$ is obtained from (A8) by replacing $p^{*}$ with $p^{o}$ and the scaled density $f^{o}$ is obtained from (A28) by replacing $z_{e}$ with $z_{e}^{o}$. Q.E.D.

\section{Appendix B. Computation of Stationary Equilibrium}

This appendix provides explicit formulas and an algorithm to compute the stationary equilibrium with endogenous leverage $\left(b^{o}, p^{o}, z_{e}^{o}, N^{o}, \mu^{o}\right)$ described in Section III.B for the case with positive fixed cost $c_{f}>0$. The algorithm consists of the following steps:

Step 1. Solve for the optimal coupon rate $b^{o}$ and the equilibrium output price $p^{o}$ using the system of two equations (34) and (41). Specifically, rewrite (34) and (41) in an explicit form

$$
\begin{aligned}
\frac{\tau}{r+\eta}\left[1-\int_{\underline{z}}^{\bar{z}}\left(\frac{z}{z_{d}}\right)^{\vartheta} \zeta(d z)\right]= & \frac{-\vartheta}{\gamma} \frac{\tau b}{(r+\eta)\left(b+c_{f}\right)} \int_{\underline{z}}^{\bar{z}}\left(\frac{z}{z_{d}}\right)^{\vartheta} \zeta(d z) \\
& +\frac{1-\alpha}{\gamma\left(b+c_{f}\right)}\left[A^{\prime}\left(z_{d} ; p\right) z_{d}-\vartheta A\left(z_{d} ; p\right)\right] \\
& \times \int_{\underline{z}}^{\bar{z}}\left(\frac{z}{z_{d}}\right)^{\vartheta} \zeta(d z)
\end{aligned}
$$




$$
\begin{aligned}
c_{e}= & \int_{\underline{z}}^{\bar{z}} A(z ; p) \zeta(d z)+\frac{b \tau}{r+\eta}\left[1-\int_{\underline{z}}^{\bar{z}}\left(\frac{z}{z_{d}}\right)^{\vartheta} \zeta(d z)\right] \\
& -(1-\alpha) A\left(z_{d} ; p\right) \int_{\underline{z}}^{\bar{z}}\left(\frac{z}{z_{d}}\right)^{\vartheta} \zeta(d z) .
\end{aligned}
$$

Substituting the expressions for $z_{A}, z_{d}$, and $A(z, p)$ in equations (25), (29), and (22), respectively, into the above two equations yields a system of two nonlinear equations for two unknowns, $(b, p)$. Any standard nonlinear equation solver can deliver numerical solutions for $\left(b^{o}, p^{o}\right)$.

Step 2. Solve for the exit threshold $z_{e}^{o}$. Once $\left(b^{o}, p^{o}\right)$ is obtained, use (29) to compute $z_{e}^{o}=z_{d}\left(b^{o} ; p^{o}\right)$.

Step 3. Solve for the scaled density $f^{o}$ of the stationary distribution $\mu^{o}$. The expression for $f^{o}$ is the same as that given in (A28), but $z_{e}$ must be replaced by $z_{e}^{o}$ in the support and also in the coefficients $A_{1}, A_{2}, G_{1}, G_{2}$, and $H_{1}$.

Step 4. Solve for the entry rate $N^{o}$. The expression for $N^{o}$ is the same as that given in (A8), but $p^{*}$ must be replaced by $p^{o}$.

The expressions for other important equilibrium variables are described as follows:

1. Industry output. Use the industry demand (1) to derive

$$
Y\left(\mu^{o}, b^{o} ; p^{o}\right)=\left(p^{o}\right)^{-\varepsilon}
$$

2. Turnover rate. It is defined as the ratio of the entry rate to the mass of incumbents. Since the mass of incumbents (size of the industry) is given by

$$
M^{o}=\int_{z_{e}^{o}}^{\infty} \mu^{o}(d z)=N^{o} \int_{z_{e}^{o}}^{\infty} f^{o}(z) d z
$$

the turnover rate $N^{o} / M^{o}$ is given by

$$
\frac{N^{o}}{M^{o}}=\frac{1}{\int_{z_{e}^{o}}^{\infty} f^{o}(z) d z}
$$

3. Average industry agency costs. The absolute value is defined as the total industry agency costs divided by the mass of incumbents

$$
\frac{1}{M^{o}} \int_{z_{e}^{o}}^{\infty} c_{A}\left(z, b^{o} ; p^{o}\right) \mu^{o}(d z)=\frac{N^{o}}{M^{o}} \int_{z_{e}^{o}}^{\infty} c_{A}\left(z, b^{o} ; p^{o}\right) f^{o}(z) d z
$$

The relative value is defined as the percentage of the average industry first-best firm value 


$$
\frac{\frac{1}{M^{o}} \int_{z_{e}^{o}}^{\infty} c_{A}\left(z, b^{o} ; p^{o}\right) \mu^{o}(d z)}{\frac{1}{M^{o}} \int_{z_{e}^{o}}^{\infty} v^{F B}\left(z, b^{o} ; p^{o}\right) \mu^{o}(d z)}=\frac{\int_{z_{e}^{o}}^{\infty} c_{A}\left(z, b^{o} ; p^{o}\right) f^{o}(z) d z}{\int_{z_{e}^{o}}^{\infty} v^{F B}\left(z, b^{o} ; p^{o}\right) f^{o}(z) d z} .
$$

4. Average industry leverage. It is defined as the ratio of the average industry debt value to the average industry firm value:

$$
\frac{\frac{1}{M^{o}} \int_{z_{e}^{o}}^{\infty} d\left(z, b^{o} ; p^{o}\right) \mu^{o}(d z)}{\frac{1}{M^{o}} \int_{z_{e}^{o}}^{\infty} v\left(z, b^{o} ; p^{o}\right) \mu^{o}(d z)}=\frac{\int_{z_{e}^{o}}^{\infty} d\left(z, b^{o} ; p^{o}\right) f^{o}(z) d z}{\int_{z_{e}^{o}}^{\infty} v\left(z, b^{o} ; p^{o}\right) f^{o}(z) d z} .
$$

\section{REFERENCES}

Andrade, Gregor, and Steven N. Kaplan, 1998, How costly is financial (not economic) distress? Evidence from highly leveraged transactions that became distressed, Journal of Finance 53, 1443-1493.

Baker, Malcolm, and Jeffrey Wurgler, 2002, Market timing and capital structure, Journal of Finance 57, 1-32.

Barclay, Michael J., Ewan Morellec, and Clifford W. Smith Jr., 2006, On the debt capacity of growth options, Journal of Business (forthcoming).

Black, Fischer, and Myron Scholes, 1973, The pricing of options and corporate liabilities, Journal of Political Economy 81, 637-659.

Bolton, Patrick, and David Scharfstein, 1990, A theory of predation based on agency problems in financial contracting, American Economic Review 80, 93-106.

Bradley, Michael, Gregg A. Jarrell, and E. Han Kim, 1984, On the existence of an optimal capital structure, Journal of Finance 39, 857-878.

Brady, B., and R. Bos, 2002, Record Defaults in 2001: The Result of Poor Credit Quality and a Weak Economy (Standard \& Poor's, New York).

Brander, James A., and Tracy R. Lewis, 1986, Oligopoly and financial structure: The limited liability effect, American Economic Review 76, 956-970.

Brander, James A., and Tracy R. Lewis, 1988, Bankruptcy costs and the theory of oligopoly, Canadian Journal of Economics 21, 221-243.

Brennan, Michael J., and Eduardo S. Schwartz, 1984, Optimal financial policy and firm valuation, Journal of Finance 39, 593-607.

Caballero, Ricardo J., and Eduardo M.R.A. Engel, 1999, Explaining investment dynamics in U.S. Manufacturing: A generalized (S,s) approach, Econometrica 67, 783-826.

Caves, Richard E., 1998, Industrial organization and new findings on the turnover and mobility of firms, Journal of Economic Literature 36, 1947-1982.

Chevalier, Judith A., 1995a, Capital structure and product-market competition: Empirical evidence from the supermarket industry, American Economic Review 85, 415-435.

Chevalier, Judith A., 1995b, Do LBO supermarkets charge more? An empirical analysis of the effects of LBOs on supermarket pricing, Journal of Finance 50, 1095-1112.

Cooley, Thomas F., and Vincenzo Quadrini, 2001, Financial markets and firm dynamics, American Economic Review 91, 1286-1310.

Dasgupta, Sudipto, and Sheridan Titman, 1998, Pricing strategy and financial policy, Review of Financial Studies 11, 705-737.

Dixit, Avinash, 1989, Entry and exit decisions under uncertainty, Journal of Political Economy 97, 620-638. 
Dixit, Avinash, and Robert Pindyck, 1994, Investment Under Uncertainty (Princeton University Press, Princeton, NJ).

Duffie, Darrell, and David Lando, 2001, Term structures of credit spreads with incomplete accounting information, Econometrica 69, 633-664.

Dunne, Timothy, Mark J. Roberts, and Larry Samuelson, 1988, Patterns of firm entry and exit in U.S. manufacturing industries, Rand Journal of Economics 19, 495-515.

Ericson, Richard, and Ariel Pakes, 1995, Markov-perfect industry dynamics: A framework for empirical work, Review of Economic Studies 62, 53-82.

Feldman, Mark, and Christian Gilles, 1985, An expository note on individual risk without aggregate uncertainty, Journal of Economic Theory 35, 26-32.

Fries, Steven, Marcus Miller, and William Perraudin, 1997, Debt in industry equilibrium, Review of Financial Studies 10, 39-67.

Goldstein, Robert, Nengjiu Ju, and Hayne E. Leland, 2001, An EBIT-based model of dynamic capital structure, Journal of Business 74, 483-512.

Graham, John R., 1996, Proxies for the corporate marginal tax rate, Journal of Financial Economics 42, 187-221.

Graham, John R., 2000, How big are the tax benefits of debt? Journal of Finance 55, 1901-1941.

Hackbarth, Dirk, Jianjun Miao, and Erwan Morellec, 2004, Capital structure, credit risk, and macroeconomic conditions, Working paper, University of Rochester.

Harris, Milton, and Artur Raviv, 1991, The theory of capital structure, Journal of Finance 46, $297-355$.

Harrison, Michael J., and David M. Kreps, 1979, Martingales and arbitrage in multiperiod securities markets, Journal of Economic Theory 20, 381-408.

Hopenhayn, Hugo A., 1992a, Entry, exit, and firm dynamics in long run equilibrium, Econometrica $60,1127-1150$.

Hopenhayn, Hugo A., 1992b, Exit, selection, and the value of firms, Journal of Economic Dynamics and Control 16, 621-653.

Hopenhayn, Hugo A., and Richard Rogerson, 1993, Job turnover and policy evaluation: A general equilibrium analysis, Journal of Political Economy 101, 915-938.

Jensen, Michael C., 1986, Agency costs of free cash flow, corporate finance and takeovers, American Economic Review 76, 323-329.

Jensen, Michael C., and William H. Meckling, 1976, Theory of the firm: Managerial behavior, agency costs, and ownership structure, Journal of Financial Economics 4, 305-360.

Jovanovic, Boyan, 1982, Selection and the evolution of industry, Econometrica 50, 649-670.

Ju, Nengjiu, Robert Parrino, Allen M. Poteshman, and M.S. Weisbach, 2003, Horses and rabbits? Optimal dynamic capital structure from shareholder and manager perspectives, Working paper, University of Texas at Austin.

Judd, Kenneth L., 1985, The law of large numbers with a continuum of IID random variables, Journal of Economic Theory 35, 19-25.

Karatzas, Ioannis, and Steven E. Shreve, 1991, Brownian Motion and Stochastic Calculus (2nd Edition, Springer Verlag, Berlin).

Kovenock, Dan, and Gordon M. Phillips, 1997, Capital structure and product market behavior: An examination of plant exit and investment decisions, Review of Financial Studies 10, 767-803.

Kraus, Alan, and Robert Litzenberger, 1973, A state-preference model of optimal financial leverage, Journal of Finance 33, 911-922.

Kydland, Finn E., and Edward C. Prescott, 1982, Time to build and aggregate fluctuations, Econometrica 50, 1345-1370.

Lambrecht, Bart M., 2001, The impact of debt financing on entry and exit in a duopoly, Review of Financial Studies 14, 765-804.

Lang, Larry, Eli Ofek, and Rene M. Stulz, 1996, Leverage, investment, and firm growth, Journal of Financial Economics 40, 3-29.

Leahy, John V., 1993, Investment in competitive equilibrium: The optimality of myopic behavior, Quarterly Journal of Economics 108, 1105-1133.

Leland, Hayne E., 1994, Corporate debt value, bond covenants and optimal capital structure, Journal of Finance 49, 1213-1252. 
Leland, Hayne E., 1998, Agency costs, risk management, and capital structure, Journal of Finance 4, 1213-1243.

Leland, Hayne E., and Klaus B. Toft, 1996, Optimal capital structure, endogenous bankruptcy, and the term structure of credit spreads, Journal of Finance 51, 987-1019.

Lindenberg, Eric B., and Stephen A. Ross, 1981, Tobin's q ratio and industrial organization, Journal of Business 54, 1-32.

Mackay, Peter, and Gordon M. Phillips, 2004, How does industry affect firm financial structure? Review of Financial Studies (forthcoming).

Maksimovic, Vojislav, 1988, Capital structure in repeated oligopolies, Rand Journal of Economics 19, 389-407.

Maksimovic, Vojislav, and Gordon M. Phillips, 1998, Asset efficiency and reallocation decisions of bankrupt firms, Journal of Finance 53, 1495-1532.

Maksimovic, Vojislav, and Josef Zechner, 1991, Debt, agency costs, and industry equilibrium, Journal of Finance 46, 1619-1643.

Mauer, David C., and Alexander J. Triantis, 1994, Interactions of corporate financing and investment decisions: A dynamic framework, Journal of Finance 49, 1253-1277.

Mella-Barral, Pirre, 1995, Optimal debt exchange offers, Working paper, London School of Business.

Mello, Antonio S., and John E. Parsons, 1992, Measuring the agency costs of debt, Journal of Finance 47, 1887-1904.

Merton, Robert, 1974, On the pricing of corporate debt: The risk structure of interest rate, Journal of Finance 29, 449-469.

Miao, Jianjun, 2004, Competitive equilibria of economies with a continuum of consumers and aggregate shocks, Journal of Economic Theory (forthcoming).

Modigliani, Franco, and Merton H. Miller, 1958, The cost of capital, corporation finance and the theory of investment, American Economic Review 48, 267-297.

Modigliani, Franco, and Merton H. Miller, 1963, Corporate income taxes and the cost of capital: A correction, American Economic Review 53, 433-443.

Morellec, Erwan, 2001, Asset liquidity, capital structure and secured debt, Journal of Financial Economics 61, 173-206.

Morellec, Erwan, 2004, Can managerial discretion explain observed leverage ratios? Review of Financial Studies 17, 257-294.

Myers, Steward C., 1977, The determinants of corporate borrowing, Journal of Financial Economics 37, 189-238.

Orr, Dale, 1974, The determinants of entry: A study of the Canadian manufacturing industries, Review of Economics and Statistics 56, 58-66.

Parrino, Robert, and Michael S. Weisbach, 1999, Measuring investment distortions arising from stockholder-bondholder conflicts, Journal of Financial Economics 53, 3-42.

Phillips, Gordon M., 1995, Increased debt and industry product markets: An empirical analysis, Journal of Financial Economics 37, 189-238.

Poitevin, Michael, 1989, Financial signalling and the deep-pocket argument, Rand Journal of Economics 20, 26-40.

Rajan, Raghuram G., and Luigi Zingales, 1995, What do we know about capital structure? Some evidence from international data, Journal of Finance 50, 1421-1467.

Titman, Sheridan, and Sergey Tsyplakov, 2002, A dynamic model of optimal capital structure, Working paper, University of Texas at Austin.

Titman, Sheridan, and Roberto Wessels, 1988, The determinants of capital structure choice, Journal of Finance 43, 1-19.

Welch, Ivo, 2004, Stock returns and capital structure, Journal of Political Economy 112, 106-131.

Williams, Joseph T., 1995, Financial and industrial structure with agency, Review of Financial Studies 8, 431-474.

Zingales, Luigi, 1998, Survival of the fittest or the fattest? Exit and financing in the trucking industry, Journal of Finance 53, 905-938. 
2660 